The University of San Francisco

USF Scholarship: a digital repository @ Gleeson Library |

Geschke Center

Environmental Science

College of Arts and Sciences

2007

\title{
Plant Assemblage Composition Explains and Predicts How Biodiversity Affects Salt Marsh Functioning
}

Gary Sullivan

John Callaway

University of San Francisco, callaway@usfca.edu

Joy B. Zedler

Follow this and additional works at: http://repository.usfca.edu/envs

Part of the Environmental Sciences Commons

\section{Recommended Citation}

Gary Sullivan, John C. Callaway, and Joy B. Zedler 2007. Plant Assemblage Composition Explains and Predicts How Biodiversity Affects Salt Marsh Functioning. Ecological Monographs 77:569-590.

This Article is brought to you for free and open access by the College of Arts and Sciences at USF Scholarship: a digital repository @ Gleeson Library | Geschke Center. It has been accepted for inclusion in Environmental Science by an authorized administrator of USF Scholarship: a digital repository @ Gleeson Library | Geschke Center. For more information, please contact repository@usfca.edu. 


\title{
PLANT ASSEMBLAGE COMPOSITION EXPLAINS AND PREDICTS HOW BIODIVERSITY AFFECTS SALT MARSH FUNCTIONING
}

\author{
Gary Sullivan, ${ }^{1}{ }^{\text {John }}$ C. Callaway, ${ }^{2}$ and Joy B. Zedler ${ }^{3,4}$ \\ ${ }^{1}$ The Wetlands Initiative, 53 West Jackson Boulevard, Chicago, Illinois 60604 USA \\ ${ }^{2}$ Department of Environmental Science, University of San Francisco, 2130 Fulton Street, San Francisco, California 94117 USA \\ ${ }^{3}$ Botany Department and Arboretum, University of Wisconsin, 430 Lincoln Drive, Madison, Wisconsin 53706 USA
}

\begin{abstract}
Knowing that diverse plantings enhanced biomass and nitrogen $(\mathrm{N})$ accumulation in a restored California salt marsh, we asked if the "biodiversity effect" was due to species selection or complementarity. In a two-year greenhouse experiment, we found positive biodiversity effects on total, root, and shoot biomass, total and root $\mathrm{N}$ crop, and on biomass and $\mathrm{N}$ allocation; negative effects on root and shoot $\mathrm{N}$ concentration; and no effect on shoot $\mathrm{N}$ crop. Overyielding among trios and sextets was supported by significant deviations in observed yield from that expected relative to solo yields $\left(D_{\mathrm{T}}\right)$. However, both trios and sextets strongly underyielded relative to the highest yielding solo in the assemblage $\left(D_{\max }\right)$ in all attributes, and to the dominant species in the assemblage $\left(D_{\mathrm{dom}}\right)$ in most attributes. When we decomposed biodiversity effects on shoot characteristics, selection effects primarily drove over- and underyielding. The only complementarity effect was underyielding of sextet shoot biomass. These analyses were possible because we replicated assemblages and evaluated 11 response variables. One species (Salicornia virginica) dominated functioning when present; when absent, another dominated (e.g., Frankenia salina). Effects varied with the response tested, however. For both shoot biomass and $\mathrm{N}$ crop, S. virginica was the dominant overyielding species (based on $D_{i j}$ and comparisons of trios \pm target species). For shoot $\mathrm{N}$ concentration, however, the dominant was Triglochin concinna, a species that had low biomass but was capable of reducing assemblage performance, presumably by concentrating $\mathrm{N}$.

Evidence for strong species selection effects led us to predict that three species would eventually dominate our parallel field experiment that tested the same assemblages. Exactly that happened in nine years, but (we predict) without losing function, because the site retained the three highest-performing species. Biodiversity loss was nonrandom in the field, and because trios with two top performers sustained critical functions in the greenhouse, we predict that many functions will not decline, even if the salt marsh becomes dominated by a single species, e.g., S. virginica. Unmeasured functions (e.g., resilience) might not persist, however. Knowing how assemblages perform made biodiversity-ecosystem function theory both explanatory and predictive.
\end{abstract}

Key words: assemblages; BEF theory; biodiversity; biomass; complementarity; function; nitrogen; root: shoot ratios; Salicornia virginica; salt marsh; selection effects.

\section{INTRODUCTION}

A wealth of research relating biodiversity to ecosystem functioning recognizes a pattern that Darwin (1859) observed: productivity seems higher where more species co-occur. The need to understand such a relationship is central to the argument that diversity must be conserved for its functional value (reviewed by Srivastava and Vellend 2005). A related concept is that the functions provided by diversity should aid the persistence of species-rich vegetation.

Experimentalists have shown that increased richness of plant species is correlated with increased productivity (Naeem et al. 1994, 1995, 1996, Hector et al. 1999, Tilman et al. 2001, Fridley 2002, Callaway et al. 2003), nutrient retention (Ewel et al. 1991), stability, resiliency,

Manuscript received 22 November 2006; revised 28 March 2007; accepted 4 April 2007. Corresponding Editor: S. Naeem.

${ }^{4}$ Corresponding author. E-mail: jbzedler@wisc.edu and reliability (Chapin et al. 1992, Tilman and Downing 1994, Naeem and Li 1997, Yachi and Loreau 1999, Cottingham et al. 2001, Loreau et al. 2002, Tilman et al. 2006), canopy complexity (Keer and Zedler 2002), invasion resistance (Tilman 1997, Knops et al. 1999, Naeem et al. 2000, Symstad 2000, Hector et al. 2001, Kennedy et al. 2002, Lindig-Cisneros and Zedler 2002, Fargione and Tilman 2005), and decreased foliar pathogen loads (Mitchell et al. 2002). There now is considerable consensus that biodiversity affects ecosystem functioning in a range of ecosystems and environmental conditions (Balvanera et al. 2006, Cardinale et al. 2006, Naeem 2006), although earlier studies indicated that the relationship is weak or lacking (Wardle et al. 1997, Hector et al. 2000, Schwartz et al. 2000, Wardle 2001), or that the ability to detect richness effects depends on additional variables, such as the diversity of functional groups present (Aarssen 1997, Hooper and 
Vitousek 1997, Huston 1997, Tilman et al. 1997), the response variable measured (Dukes 2002, Keer and Zedler 2002), the concentration of atmospheric $\mathrm{CO}_{2}$ (Reich et al. 2001), soil fertility (Fridley 2002), the level of phenological complementarity among member species (Hooper and Vitousek 1997, Stevens and Carson 2001), the interaction strengths of species included in the experiment (Kokkoris et al. 2002), trophic levels considered (Duffy et al. 2001, O'Connor and Crowe 2005, Cardinale et al. 2006), and the duration of community development (Tilman et al. 2001).

Despite many tests of biodiversity-ecosystem function (BEF) theory, Hooper et al. (2005) concluded that BEF theory is not yet predictive, although it is explanatory, and Srivastava and Vellend (2005) found little relevance of BEF findings to conservation except in the restoration arena. Three uncertainties related to conservation are (1) which mechanisms underlie diversity-function relationships (Diaz and Cabido 2001, Fridley 2001, Fukami et al. 2001, Loreau et al. 2001, Cameron 2002, Cardinale et al. 2002, Naeem 2002a, b, Hooper et al. 2005), (2) how individual species or the individual characteristics of species or functional groups affect function within and across ecosystems (Schwartz et al. 2000, Leps et al. 2001, Mittelbach et al. 2001, Walker and Langridge 2002), and (3) how diversity contributes to ecosystem resilience and sustainability (Wardle et al. 1997, Dukes 2001, 2002, Fukami et al. 2001, Wardle 2001, Pfisterer and Schmid 2002, Srivastava and Vellend 2005, Tilman et al. 2006).

The southern Californian salt marsh plain is an ideal natural system for exploring diversity effects and their relevance to conservation, because the small species pool aids the detection of effects (Vitousek and Hooper 1993), because eight halophytes naturally co-occur in assemblages of one to six species per $0.1 \mathrm{~m}^{2}$ and $0.25 \mathrm{~m}^{2}$ (Zedler 1977, Zedler et al. 1999, Morzaria-Luna et al. 2004), and because the eight species have life history and morphological attributes that suggest the potential for complementarity effects (Sullivan and Zedler 1999). Our field experiment tested BEF theory using $2 \times 2 \mathrm{~m}$ plots planted with one species (solos), three species (trios), or six species (sextets). Established in April 1997 and subsampled in January 2000, the field experiment produced a "diversity effect" of greater biomass and $\mathrm{N}$ crop for sextets than solos (Callaway et al. 2003).

Here, we used a greenhouse experiment to explore mechanisms underlying that diversity effect, employing the same 8 solos, 16 trios, and 16 sextets (each replicated eightfold). We employed three overyielding analyses to determine if multispecies assemblages performed better or worse than expected in the absence of diversity effects. We calculated three deviation indices $\left(D_{\mathrm{T}}, D_{\max }\right.$, and $\left.D_{\text {dom }}\right)$ to determine what processes might be responsible for an over- or underyielding response (Hector 1998, Loreau 1998, Loreau and Hector 2001, Hector et al. 2002). In addition, we decomposed the overall net biodiversity effect (NBE) on shoot characteristics into selection and complementarity effects
(Loreau and Hector 2001). Selection effects (SE) occur when an assemblage is dominated by one or more species whose yields are either higher (positive SE) or lower (negative SE) than the average monotypic yield and is measured as the covariance between the monotypic yield of species and their change in relative yield when grown in mixture (Loreau and Hector 2001, Spehn et al. 2005). Complementarity effects (CE) primarily result from positive or negative species interactions (e.g., resource partitioning, facilitating, or interference) leading to species yields exceeding that expected from their monotypes. SE may be caused by sampling effects due to the increased probability of having a dominant species in richer assemblages, but they may also result from the increased probability of having a complementary or facilitative pair or group of species (Loreau and Hector 2001, Hooper and Dukes 2004). Because CE and SE are additive, positive or negative species interactions may contribute to each effect (Loreau and Hector 2001, Petchey 2003).

We also determined how each species affected function, and we predicted the ability of diverse assemblages to persist in the field, thus exploring both the explanatory and predictive capabilities of BEF theory, as called for by Hooper et al. (2005). To establish predictions from BEF theory, we reasoned that strong selection effects of a positive nature (e.g., overyielding due to the presence of a particular species) would, over time, lead to dominance by the overyielding species. Conversely, we reasoned that strong, positive interspecific interactions (complementarity or facilitation) would promote the persistence of diverse assemblages over the long term.

In this experiment, we hypothesized that (1) each species grown solo would perform uniquely across the range of characteristics considered, as in the field experiment (Callaway et al. 2003); (2) sextets would outperform solos, with trios intermediate, similar to results in the field; (3) strong performers (in solo) would greatly influence assemblage yield; (4) both selection and complementarity effects would be detected where measurable; and (5) the strength and magnitude of all effects would vary with the attribute assessed. Last, we used the greenhouse results to interpret outcomes in the field experiment after nine years and to extend predictions into the future.

\section{Methods}

The greenhouse experiment (see Plate 1) tested the same eight halophytes (Table 1) and the same randomly drawn assemblages (Table 2) as in the field experiment but added eightfold replication of each assemblage. We did not consider functional group richness or identity, because these eight species do not segregate into groups (Sullivan and Zedler 1999). We tested in detail the effects of the three most abundant marsh-plain species: the regional dominant Salicornia virginica (Zedler et al. 2001), the second and third most abundant species at 
TABLE 1. The eight common halophytes of the southern California marsh plain, with species codes and descriptions. All but two species (Se, Sb) are long-lived perennials.

\begin{tabular}{lll}
\hline \hline \multicolumn{1}{c}{ Halophyte } & Code & \multicolumn{1}{c}{ Description } \\
\hline Batis maritima L. & $\mathrm{Bm}$ & trailing succulent forb \\
Frankenia salina (Molina) Johnston & $\mathrm{Fs}$ & suffrutescent subshrub \\
Jaumea carnosa Gray & $\mathrm{Jc}$ & trailing succulent forb \\
Limonium californicum Heller & $\mathrm{Lc}$ & leafy rosette forb \\
Salicornia bigelovii Torrey & $\mathrm{Sb}$ & upright succulent annual forb \\
Suaeda esteroa Ferren and Whitmore & $\mathrm{Se}$ & short-lived succulent forb \\
Salicornia virginica L. & $\mathrm{Sv}$ & upright succulent subshrub \\
Triglochin concinna Burtt Davy & $\mathrm{Tc}$ & graminoid succulent, ephemeral shoots
\end{tabular}

Tijuana River National Estuarine Research Reserve, California, USA (hereafter Tijuana Estuary), Jaumea carnosa and Frankenia salina (Zedler and West, in press), plus Triglochin concinna, which negatively influenced other species in previous experiments (Sullivan and Zedler 1999). We assessed 11 response variables, including above- and belowground attributes, and we evaluated relative yields, as well as selection and complementarity effects, expecting that the diversity effect could differ with the variable assessed or the index used to detect effects.

All plants were grown from seed in a greenhouse at San Diego State University, San Diego, California, USA, beginning in the same year as the field experiment (1997). The experimental treatments (plantings of different composition and richness) were maintained for two growing seasons (1997 and 1998). We simulated intertidal conditions and controlled water levels, salinity, and nutrient inputs to reduce confounding factors (Lamont 1995, Fridley 2002). All species became sexually reproductive during the study, allaying concerns about experimentation with immature vegetation (Huston et al. 2000).

\section{Experimental design}

We used a randomized block design with each block being a table in the greenhouse that held one replicate of each treatment. Replicates were re-randomized within blocks monthly throughout the experiment. Plants were grown in one-, three-, and six-species assemblages (solos, trios, and sextets) with evenness held constant at six plants per pot; a non-planted control was used to sample soil salinity (a destructive process). Our randomly drawn assemblages included all eight of the most common species found in nearby reference systems (Table 2). Trios and sextets were selected by randomly choosing 15 of the possible 56 trios and 15 of the possible 28 sextets. Our sextets contained $75 \%$ of the members of the eightspecies pool and thus had high overlap in composition and low variability in performance (Cottingham et al. 2001). We added an additional trio and sextet that were the most common in $0.25-\mathrm{m}^{2}$ plots at Tijuana Estuary in 1974 (Zedler 1977) but missed by the random draws; these were BmSbSv and BmFsJcSbSeSv (species codes in Table 1). All of these assemblages occur naturally in salt marshes within the region (Morzaria-Luna et al. 2004).
These 32 assemblages, plus the eight solos and an unplanted control (41 treatments) were replicated eightfold for a total of 328 microcosms.

\section{Microcosms}

Each microcosm consisted of a $23 \mathrm{~cm}$ diameter $\times 38$ $\mathrm{cm}$ deep plastic pot housed in a 19-L (5-gallon) bucket without drainage. Each pot held $35 \mathrm{~cm}$ of low nutrient sandy soil $\left(13500 \mathrm{~cm}^{3}, 0.033 \mathrm{mg}\right.$ TKN/g soil, $70 \%$ sand, $19 \%$ silt, and $11 \%$ clay) that had been sifted over a 0.65 $\times 0.65 \mathrm{~cm}$ mesh screen. To insure that the assemblages were grown in an environment with the same microflora found in native marsh sediments, each microcosm was inoculated with a homogenous slurry containing $\sim 0.5 \mathrm{~g}$ of native soil from the marsh plain of Tijuana Estuary.

Seeds of the eight species were collected from Tijuana Estuary in December 1996; seeds were germinated in flats and transplanted to microcosms after 8-9 weeks. We planted seedlings in a circular array. For trios, species' positions were alternated to promote maximum interspecific interaction. For sextets, position was assigned randomly, but order was then held constant for each replicate to standardize the initial local competitive environment, just as it was among trios by default.

TABLE 2. Multispecies assemblages used in the experiment.

\begin{tabular}{lc}
\hline \hline Trios & \multicolumn{1}{c}{ Sextets } \\
\hline Bm Fs Lc & Bm Fs Jc Lc Sb Sv \\
Bm Fs Sv & Bm Fs Jc Lc Sb Tc \\
Bm Lc Se & Bm Fs Jc Lc Se Tc \\
Bm Sb Sv & Bm Fs Jc Sb Se Sv \\
Bm Sb Tc & Bm Fs Jc Sb Sv Tc \\
Fs Jc Sb & Bm Fs Jc Se Sv Tc \\
Fs Se Sv & Bm Fs Lc Sb Se Sv \\
Fs Sv Tc & Bm Fs Lc Se Sv Tc \\
Jc Lc Se & Bm Jc Lc Sb Se Sv \\
Jc Lc Sv & Bm Jc Lc Se Sv Tc \\
Jc Lc Tc & Bm Jc Sb Se Sv Tc \\
Jc Sb Sv & Fs Jc Lc Sb Se Tc \\
Jc Sb Tc & Fs Jc Lc Sb Sv Tc \\
Jc Se Sv & Fs Jc Sb Se Sv Tc \\
Lc Se Tc & Fs Lc Sb Se Sv Tc \\
Se Sv Tc & Jc Lc Sb Se Sv Tc \\
\hline
\end{tabular}

Notes: Trios were randomly chosen from the pool of 56 potential combinations; sextets were randomly chosen from the pool of 28. Species codes are in Table 1. 

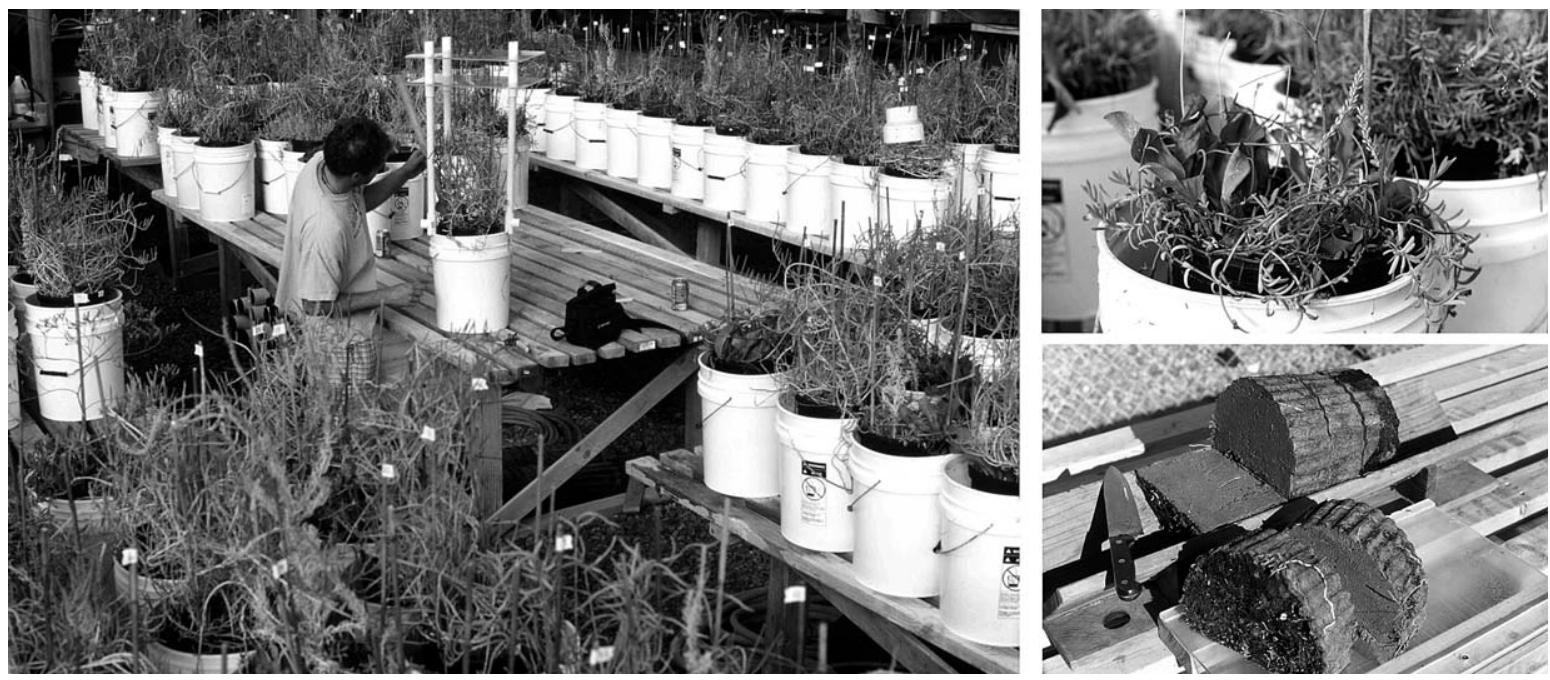

Plate 1. Greenhouse experiment showing a trio in the upper right with Limonium californicum (broad leaves), Jaumea carnosa (trailing stems with opposite leaves), and Triglochin concinna (dry grass-like leaves and fruiting stalks) and, in the lower right, the sectioning of the root zones prior to root washing. Photo credit: G. Sullivan.

Soil salinity was increased over the first 16 weeks with the biweekly addition of $1.0 \mathrm{~L}$ of seawater to the microcosm well until it reached 34 parts per thousand (ppt). Transpiration and evaporative losses were replaced with tap water to maintain the water level at 10$12 \mathrm{~cm}$ above the bottom of each microcosm throughout the experiment. Holes at the bottom of each pot allowed water to drain or move up the soil column. To confine shoots to their own microcosm, we attached two $25 \mathrm{~cm}$ diameter galvanized wire rings to three bamboo stakes at 10- and 25-cm heights in December 1997.

From 22 June 1997 through 26 October 1998, we flooded each microcosm twice monthly for 24 hours with dilute seawater (salinity $15 \mathrm{ppt}$ ) to mimic marshplain flooding and keep soil salinities near field levels (moderately hypersaline). Flooding covered the soil surface to a depth of at least $3 \mathrm{~cm}$, until it was drained to $12 \mathrm{~cm}$ above the bottom of the bucket.

We fertilized microcosms on alternate flooding cycles to mimic seasonal patterns of tidal nutrient inputs. From 2 June through 2 October 1997, we fertilized microcosms with a $500-\mathrm{mL}$ solution of Peters soluble 217-7 commercial fertilizer (J. R. Peters, Allentown, Pennsylvania, USA) poured over the soil surface after draining the flooding cycle. Concentration was initially low at $0.2 \mathrm{~g} / \mathrm{L}\left(20.60 \mathrm{mg} \mathrm{NH}{ }_{4}^{+} / \mathrm{kg}\right.$ water, $20.93 \mathrm{mg}$ urea $/ \mathrm{kg}$ water, $11.54 \mathrm{mg} \mathrm{K}^{+} / \mathrm{kg}$ water, $6.02 \mathrm{mg} \mathrm{PO}_{4}^{-} / \mathrm{kg}$ water), then increased to $1.5 \mathrm{~g} / \mathrm{L}$ after the second addition $\left(154.48 \mathrm{mg} \mathrm{NH}_{4}{ }^{+} / \mathrm{kg}\right.$ water, $156.97 \mathrm{mg}$ urea $/ \mathrm{kg}$ water, $86.58 \mathrm{mg} \mathrm{K}^{+} / \mathrm{kg}$ water, $45.16 \mathrm{mg} \mathrm{PO}_{4}^{-} / \mathrm{kg}$ water, half the recommended dosage for maintaining potted plants). Fertilization during the second year resumed 1 March 1998 and continued through 4 September 1998. Concentration during year 2 was alternated monthly at 0.2 and $1.5 \mathrm{~g} / \mathrm{L}$.

\section{Harvest, sample processing, and nitrogen analysis}

We harvested biomass from 1 November to 4 December 1998. We separated aboveground biomass (hereafter shoots) by species, then rinsed shoots over a fine screen to remove surface salts. Detrital material that sloughed off during the experiment was collected separately. Belowground biomass (hereafter roots) in multispecies assemblages could not be distinguished by species and was composited within a pot, although roots were separated into vertical strata. Before separating roots from soil, we removed a $0.5-\mathrm{cm}$ thick vertical section of soil that was cut edge to edge from the top to the bottom through the center of each pot. This section was weighed and dried separately to calculate dry: wet mass ratios and soil $\mathrm{N}$ concentration. The remaining soil was sectioned into five 6-cm horizontal strata and weighed wet (the original $35-\mathrm{cm}$ column had settled to $\sim 30 \mathrm{~cm}$ ). Roots from each stratum were rinsed over a USS 35 mesh screen $(0.45-\mathrm{mm}$ opening). Because differences in root biomass among assemblages in the upper three strata were not significant but were significant in the lower two (waterlogged) strata, we chose the proportion of roots allocated to the waterlogged soil strata as a single variable reflecting niche space utilization.

Because species differed in dry mass (DM) due to differences in ash content (e.g., Fs is a non-succulent with $8 \%$ of $\mathrm{DM}$ in ash, while Jc and Sv are saltaccumulating succulents at $29 \%$ and $23 \%$ ash, respectively), we used ash-free dry mass (AFDM) as the measure of biomass accumulation. Plant tissue was dried at $65^{\circ} \mathrm{C}$, ground with a Wiley mill, and passed through a 40-mesh screen (420- $\mu$ opening) before subsampling for ash content and $\mathrm{N}$ concentration. Because ash-free dry mass measures are extremely laborious, we determined 
TABLE 3. Comparison of trios and sextets in the number of positive $(+)$ and negative $(-)$ deviations, calculated as in Table 4.

\begin{tabular}{|c|c|c|c|c|c|c|c|c|c|c|c|c|c|c|c|c|c|c|c|c|}
\hline \multirow{3}{*}{$\begin{array}{l}\text { No. deviations } \\
\text { among } 16 \text { trios } \\
\text { and } 16 \text { sextets }\end{array}$} & \multicolumn{4}{|c|}{$D_{\mathrm{T}}$} & \multicolumn{4}{|c|}{$D_{\max }$} & \multicolumn{4}{|c|}{$D_{\text {dom }}$} & \multicolumn{4}{|c|}{$D_{\mathrm{CE}}$} & \multicolumn{4}{|c|}{$D_{\mathrm{SE}}$} \\
\hline & \multicolumn{2}{|c|}{ Trios } & \multicolumn{2}{|c|}{ Sextets } & \multicolumn{2}{|c|}{ Trios } & \multicolumn{2}{|c|}{ Sextets } & \multicolumn{2}{|c|}{ Trios } & \multicolumn{2}{|c|}{ Sextets } & \multicolumn{2}{|c|}{ Trios } & \multicolumn{2}{|c|}{ Sextets } & \multicolumn{2}{|c|}{ Trios } & \multicolumn{2}{|c|}{ Sextets } \\
\hline & + & - & + & - & + & - & + & - & + & - & + & - & + & - & + & - & + & - & + & - \\
\hline Total AFDM & 7 & 2 & 14 & 0 & 0 & 11 & 0 & 15 & & & & & & & & & & & & \\
\hline Root AFDM & 9 & 0 & 16 & 0 & 0 & 10 & 0 & 16 & & & & & & & & & & & & \\
\hline Shoot AFDM & 2 & 4 & 3 & 2 & 0 & 14 & 0 & 16 & 0 & 7 & 0 & 10 & 0 & 2 & 0 & 2 & 5 & 5 & 7 & 0 \\
\hline AFDM R:S ratio & 5 & 4 & 3 & 2 & 0 & 14 & 0 & 16 & & & & & & & & & & & & \\
\hline Percentage deep roots $\dagger$ & 4 & 2 & 2 & 1 & 0 & 15 & 0 & 16 & & & & & & & & & & & & \\
\hline Total N crop & 6 & 1 & 7 & 0 & 0 & 11 & 0 & 16 & & & & & & & & & & & & \\
\hline Root N cro & 4 & 1 & 6 & 0 & 0 & 12 & 0 & 16 & & & & & & & & & & & & \\
\hline Shoot N crop & 0 & 4 & 0 & 4 & 0 & 15 & 0 & 16 & 0 & 4 & 0 & 4 & 0 & 0 & 0 & 2 & 1 & 6 & 0 & 4 \\
\hline Root $\mathrm{N}$ concentration & 1 & 6 & 0 & 10 & 0 & 12 & 0 & 16 & & & & & & & & & & & & \\
\hline Shoot $\mathrm{N}$ concentration & 1 & 8 & 0 & 13 & 0 & 14 & 0 & 16 & 0 & 11 & 0 & 16 & 1 & 2 & 0 & 2 & 1 & 12 & 0 & 15 \\
\hline N R:S ratio & 6 & 0 & 4 & 0 & 0 & 13 & 0 & 16 & & & & & & & & & & & & \\
\hline Totals & 45 & 32 & 55 & 32 & 0 & 141 & 0 & 175 & 0 & 22 & 0 & 30 & 1 & 4 & 0 & 6 & 7 & 23 & 7 & 19 \\
\hline
\end{tabular}

Notes: Note that $D_{\mathrm{dom}}, D_{\mathrm{CE}}$, and $D_{\mathrm{SE}}$ were determined only for shoot attributes because roots in mixed pots were inseparable by species. Calculated deviations are in Appendices F, G, and H. Abbreviations: CE, complementarity effects; SE, selection effects; AFDM, ash-free dry mass.

$\dagger$ Percentage of roots in waterlogged soil strata.

AFDM ratios for 620 of the 2496 tissue samples collected and used ratios of AFDM:dry mass to estimate AFDM for remaining samples. Total Kjeldahl nitrogen (hereafter $\mathrm{N}$ ) concentration was measured after Kjeldahl digestion of plant tissues and soil samples. All $\mathrm{N}$ concentrations were measured with an autoanalyzer (Lachat, Loveland, Colorado, USA) at the San Diego State University Analytical Laboratory.

The 5-mm vertical section of soil from each microcosm represented $4.0 \% \pm 0.61 \%$ (mean $\pm \mathrm{SE}$ ) of the entire soil column. The section was immediately weighed wet, then dried at $65^{\circ} \mathrm{C}$ for 48 hours, weighed dry, ground without separating roots to pass through a 40mesh screen, and stored in plastic bags for Kjeldahl digestion. The proportion of root AFDM and $\mathrm{N}$ in the vertical section was calculated from the microcosm root: wet soil mass ratio and added to the root totals.

\section{Response variables}

In all, we analyzed 11 assemblage response variables (Table 3). Each species shoot AFDM and N concentration, and each assemblage root AFDM and $\mathrm{N}$ concentration was used to calculate shoot, root, and total AFDM and $\mathrm{N}$ crop, and root : shoot AFDM and $\mathrm{N}$ ratios. From root AFDM per 6-cm horizon, we calculated the proportion of root AFDM in the lowest $12 \mathrm{~cm}$ of soil as an indication of species or assemblage use of waterlogged soil strata. AFDM, N concentration and crop, and root: shoot ratios indicate biomass and $\mathrm{N}$ accumulation and distribution patterns.

\section{Overyielding}

We examined overyielding within and among levels of richness by analyzing the net deviation in yield from that expected in the absence of interspecific interactions $\left(D_{\mathrm{T}}\right)$, the deviation in yield from the best yielding solo in the assemblage $\left(D_{\max }\right)$, or from the solo yield of the dominant species within the assemblage $\left(D_{\text {dom }}\right)$ (Loreau
1998, Loreau and Hector 2001, Hector et al. 2002; Table 4). $D_{\mathrm{T}}$ deviations in yield are due to the net impact of all biodiversity effects and thus provide a measure of net or non-transgressive over- or underyielding (Hector et al. 2002). $D_{\max }$ deviations may unequivocally demonstrate transgressive overyielding, where richness effects are due in part to positive interspecific interactions. That is, net assemblage performance can exceed that of the best performing species only if species are interacting together in a complementary or facilitative fashion. $D_{\text {dom }}$ deviations are a less stringent, but more relevant, measure of transgressive overyielding. Because $D_{\text {dom }}$ is calculated from the solo yield of the competitive dominant within an assemblage, it is not skewed by the presence of species that do quite well in solo, but rarely do well in the face of interspecific competition (Hooper and Vitousek 1997, Spaekova and Leps 2001, Hooper et al. 2005). It is important to note that when $D_{\text {max }}$ or $D_{\text {dom }} \leq 0$, assemblages may still overyield (i.e., $D_{\mathrm{T}}>0$ ) if the positive effects of complementary or facilitative interactions are offset by stronger dominant species effects.

Because assemblages were replicated across blocks, expected values were calculated individually for each block to account for within block variation and maintain statistical independence of samples (Wardle et al. 1997). The expected yield of the $i$ th species within a multispecies assemblage in the $j$ th block was calculated as $Y_{\mathrm{E} i j}=p_{i j} M_{i j}$, where $M_{i j}$ is the monotypic performance of the $i$ th species in the $j$ th block, and $p_{i j}$ is its proportional representation in the multispecies assemblage in the $j$ th block (Table 4). Because we could not separate root biomass or $\mathrm{N}$ by species in assemblages, we used the observed yield of all species for each microcosm in the $j$ th block $\left(\Sigma Y_{\mathrm{O} i j}=Y_{\mathrm{O}(\Sigma i) j}\right)$ for calculations involving root or total AFDM and $\mathrm{N}$. Others have estimated root biomass for each $i$ th species based on the assumption that the root: shoot ratios of 
TABLE 4. Indices calculated to characterize and test proportional deviations in yield from those expected relative to the proportional contribution of different references.

\begin{tabular}{|c|c|c|c|c|}
\hline Index & Formula & Components & Deviation & Based on \\
\hline$D_{\mathrm{T}}$ & $\begin{array}{l}\left(\Sigma Y_{\mathrm{O} i j}-\Sigma Y_{\mathrm{E} i j}\right) / \\
\Sigma Y_{\mathrm{E} i j}\end{array}$ & $\begin{array}{l}Y_{\mathrm{O} i j}=\text { observed yield } \\
Y_{\mathrm{E} i j}=p_{i j} M_{i j}=\text { expected yield; } \\
p_{i j}=\text { proportional representation; } \\
M_{i j}=\text { monotypic or solo yield }\end{array}$ & $\begin{array}{l}\text { net deviation of assemblage yield } \\
\text { relative to the proportional yield of } \\
\text { each member species grown solo; } \\
\text { differences are due to the additive } \\
\text { effects of selection and "complemen- } \\
\text { tarity" (i.e., complementarity, facili- } \\
\text { tation, interference, and/or suppres- } \\
\text { sion); a measure of the "net } \\
\text { biodiversity effect" or "non-trans- } \\
\text { gressive overyielding" }\end{array}$ & whole plants \\
\hline$D_{\max }$ & $\begin{array}{l}\left(\Sigma Y_{\mathrm{O} i j}-\max M_{i j}\right) / \\
\quad \max M_{i j}\end{array}$ & $\max M_{i j}=$ best assemblage solo & $\begin{array}{l}\text { deviation of assemblage yield relative } \\
\text { to best solo yield of a member } \\
\text { species; a measure of "transgressive } \\
\text { overyielding" }\end{array}$ & whole plants \\
\hline$D_{\text {dom }}$ & $\begin{array}{l}\left(\sum Y_{\mathrm{O} i j}-\operatorname{dom} M_{i j}\right) / \\
\quad \operatorname{dom} M_{i j}\end{array}$ & $\begin{array}{l}\text { dom } M_{i j}=\text { solo of assemblage } \\
\text { dominant }\end{array}$ & $\begin{array}{l}\text { deviation of assemblage yield relative } \\
\text { to the solo yield of the dominant } \\
\text { assemblage species; another measure } \\
\text { of transgressive overyielding }\end{array}$ & shoots only \\
\hline$D_{i}$ & $\left(Y_{\mathrm{O} i j}-Y_{\mathrm{E} i j}\right) / Y_{\mathrm{E} i j}$ & & $\begin{array}{l}\text { deviation of individual species yield } \\
\text { relative to its yield in solo }\end{array}$ & shoots only \\
\hline$D_{\mathrm{CE}}$ & $\overline{D M} / \Sigma Y_{\mathrm{E} i j}$ & $\bar{D}=$ mean $D_{i j} ; \bar{M}=$ mean $M_{i j}$ & $\begin{array}{l}\text { deviation in yield due to complemen- } \\
\text { tarity effects, also known as comple- } \\
\text { mentarity, facilitation, inhibition, } \\
\text { and suppression effects; an additive } \\
\text { component of } D_{\mathrm{T}}\end{array}$ & shoots only \\
\hline$D_{\mathrm{SE}}$ & $\begin{array}{l}N \operatorname{cov}(\Delta R Y, M) / \\
\quad \Sigma Y_{\mathrm{E} i j}\end{array}$ & & $\begin{array}{l}\text { deviation in yield due to selection } \\
\text { effects (the covariance between } \\
\text { species solo yields and their change } \\
\text { in relative yield grown in mixtures); } \\
\text { an additive component of } D_{\mathrm{T}}\end{array}$ & shoots only \\
\hline
\end{tabular}

Notes: Subscripts $i$ and $j$ refer to the observed contribution of the $i$ th species in the $j$ th block. Where yield of an assemblage required evaluation of each species' contribution, only shoot attributes could be compared, as roots were not separable in mixed pots. Note that $D_{\mathrm{CE}}$ and $D_{\mathrm{SE}}$ can only be algebraically derived from complementarity and selection effects given equal evenness at planting (from Loreau and Hector 2001).

species grown in solo allow one to predict root biomass from the shoot biomass of each species grown in mixture (as in Hooper 1998), but we found no evidence to support the assumption that these ratios apply in multispecies assemblages in the face of potentially strong species interactions.

\section{Species performance in assemblages}

We calculated the net response of each species to interspecific interactions using the individual measures of each shoot variable $\left(\mathrm{O}_{i j}\right)$ in multispecies assemblages. This allowed us to calculate $D_{i j}$, the proportional deviation of the $i$ th species in the $j$ th block grown in mixture (Table 4). $D_{i j}$ allows one to determine the direction and magnitude of each species' response to interspecific interactions. $D_{i j}>0$ indicates overyielding and $D_{i j}<0$ indicates underyielding for the $i$ th species in the $j$ th block due to species interactions. The mean of all $D_{i j}$ within an assemblage $(\bar{D})$ can differ from the net assemblage deviation $\left(D_{\mathrm{T} j}\right)$ in that it gives equal weight to each species regardless of its contribution to assemblage performance.

\section{Selection and complementarity effects}

All deviations are influenced by the potentially conflicting impacts of positive or negative selection effects (SE) due to the presence of one or more species on co-occurring assemblage members (e.g., a competitive dominant), and positive or negative species interactions due to differential partitioning of resource space, facilitation, and interference or suppression. Because complementary and facilitative interactions cannot be distinguished from each other, nor from interference or suppression where positive and negative interactions occur together, they are collectively referred to as complementarity effects, or CE (Loreau and Hector 2001, Hooper and Dukes 2004).

Because SE and CE can differ in sign and relative magnitude, it is not possible to determine the relative contribution of each through an analysis of net or transgressive overyielding. However, where $D_{i j}$ can be calculated, the net difference between observed and expected yields can be decomposed into the changes in yield due to SE and CE (Loreau and Hector 2001, Petchey 2003, Hooper and Dukes 2004). Change in expected yield due to CE is equal to $\overline{D M}$, where $\bar{M}$ is the average solo yield (Table 4). Change in expected yield due to $\mathrm{SE}$ is equal to $N \operatorname{cov}(\Delta \mathrm{RY}, \mathrm{M})$, where $N$ is the number of species in an assemblage and $\operatorname{cov}(\Delta R Y, M)$ is the covariance between the solo yield of species and their change in relative yield when grown in mixture. CE and $\mathrm{SE}$ sum to the total change in expected yield, equal to 
$D_{\mathrm{T}} \sum Y_{\mathrm{E} i j}$. Because this relationship is additive under circumstances where evenness is the same for each assemblage species, SE can be calculated as the difference between $D_{\mathrm{T}} \Sigma Y_{\mathrm{E} i j}$ and $\overline{D M}$. Deviations from expected yield due to $\mathrm{CE}\left(D_{\mathrm{CE}}\right)$ and $\mathrm{SE}\left(D_{\mathrm{SE}}\right)$ can then be calculated algebraically.

\section{Data analysis}

We performed ANOVA on (1) all assemblages; and (2) all assemblages without $\mathrm{Sv}$, using a randomized block design with assemblage as the experimental factor, and microcosm as the experimental unit. Because we replicated assemblages with different numbers of species, we could test hypotheses related to species number and composition. For comparisons among assemblages with different numbers of species, we performed specific a priori contrasts, with Dunn-Sidak adjustments to alpha (Underwood 1997). We carefully considered using a crossed and nested randomized block analysis with diversity, block $\times$ diversity, and assemblage nested within diversity as additional factors. However, this approach has little power to detect real differences among the three levels of diversity, and our primary purpose was to examine the effects of species and assemblages. In balancing the probability of committing Type II errors against an inability to make broad inferences about diversity per se, we chose not to nest assemblages within levels of diversity and to limit our generalizations to this system.

We tested hypotheses regarding the presence or absence of particular species in an analysis of trios. Sextets were not assessed because six of eight species occurred in each assemblage, making isolation of the effects of any one species difficult. We performed a posteriori contrasts $(\mathrm{df}=1)$ among assemblages with and without a subset of the eight species to examine the effects of those individual species on assemblage performance. To reduce the probability of Type I errors, we limited the number of species examined to a subset of the three dominants found in Tijuana Estuary, plus one other found to limit species in a previous experiment (Sullivan and Zedler 1999). This approach was validated with a stepwise deletion procedure in a GLM analysis of total AFDM and total N crop to rank species according to their effect on the coefficient of determination $\left(R^{2}\right)$. That analysis revealed that Sv, Jc, Fs, and Tc had the greatest effect on AFDM and N. We then performed separate a posteriori multiple contrasts among trios with and without each of those four "target" species to examine their effects on assemblage performance. The effect of each species was evaluated by calculating the Scheffé test statistic $(S)$ and comparing it against the critical value of the Scheffé adjusted $F$ statistic $\left(S_{\alpha}\right)$ to account for increased family-wise error (Winer 1971).

The performance of assemblages with a particular species could be due to the performance of that species or to its positive or negative impacts on other species. To assess the impact of particular species on assemblage performance, we examined the contribution of the four species identified previously in each of the assemblages in which they occurred. We regressed whole microcosm shoot AFDM or N crop on the shoot AFDM or N crop of each target species. Although this relationship is autocorrelated, it serves to illustrate the impact of each target species on the entire assemblage.

To determine whether any measure of overyielding (proportional deviations of observed yield from expected) was significantly greater than, less than, or equal to zero, $95 \%$ confidence intervals were calculated on each assemblage. Confidence intervals were also calculated on the assemblage means of trios and sextets to determine if they differed significantly from zero. These analyses allowed us to remove the effects of species composition while comparing the relative yield of assemblages with different numbers of species. This also allowed us to examine differences among assemblages across response variables differing in scale.

Dependent variables that did not meet the assumptions of parametric statistics were transformed: proportions were arcsine square-root transformed to improve normality, AFDM and tissue $\mathrm{N}$ crop were log-transformed where variance was proportional to the mean or to improve homoscedasticity. Alpha was set at 0.05 except where noted previously.

\section{RESUlts \\ Attributes of species grown solo}

Several results supported our first hypothesis that each species grown solo would perform uniquely across the range of response variables considered, with no two species sharing the same performance characteristic profile (Figs. 1 and 2). Three species, Fs, Jc, and Sv, outperformed all others in total AFDM and total $\mathrm{N}$ crop (Figs. 1 and 2), with Jc maximal in shoot AFDM and shoot $\mathrm{N}$ crop and Fs maximal in root AFDM and root $\mathrm{N}$ crop. Although tied with Fs and Jc for total AFDM and total $\mathrm{N}$ crop, the regional dominant species Sv did not rank first in any other attribute. Tc ranked or tied for first in root and shoot $\mathrm{N}$ concentration, AFDM root: shoot ratio, $\mathrm{N}$ root: shoot ratio, and the percentage of roots in waterlogged soil. Bm and Lc were also tied for first in total $\mathrm{N}$ crop, while the annual $\mathrm{Sb}$ ranked or tied for first in root and shoot $\mathrm{N}$ concentration.

Species differed strongly from one another in how they allocated AFDM and $\mathrm{N}$ between roots and shoots. AFDM and $\mathrm{N}$ root: shoot ratios were similar, ranging from $\sim 2.0$ ( Tc) to $\sim 0.25$ ( $\mathrm{Jc}, \mathrm{Sb}$, and $\mathrm{Se}$ ). There also were differences in how species allocated AFDM to the waterlogged soil strata, with Bm, Fs, Jc, and Tc investing more than twice as much of their roots below $18 \mathrm{~cm}(>12 \%)$ than Lc, Sb, Sv, and Se $(<6 \%)$. There was less variation among species in root and shoot $\mathrm{N}$ concentrations. The perennial graminoid Tc was tied with the annual $\mathrm{Sb}$ and the short-lived $\mathrm{Se}$ for root $\mathrm{N}$ concentration, and was tied with $\mathrm{Sb}$ for the highest shoot $\mathrm{N}$ concentration; $\mathrm{Tc}$ and $\mathrm{Sb}$ were the only two 

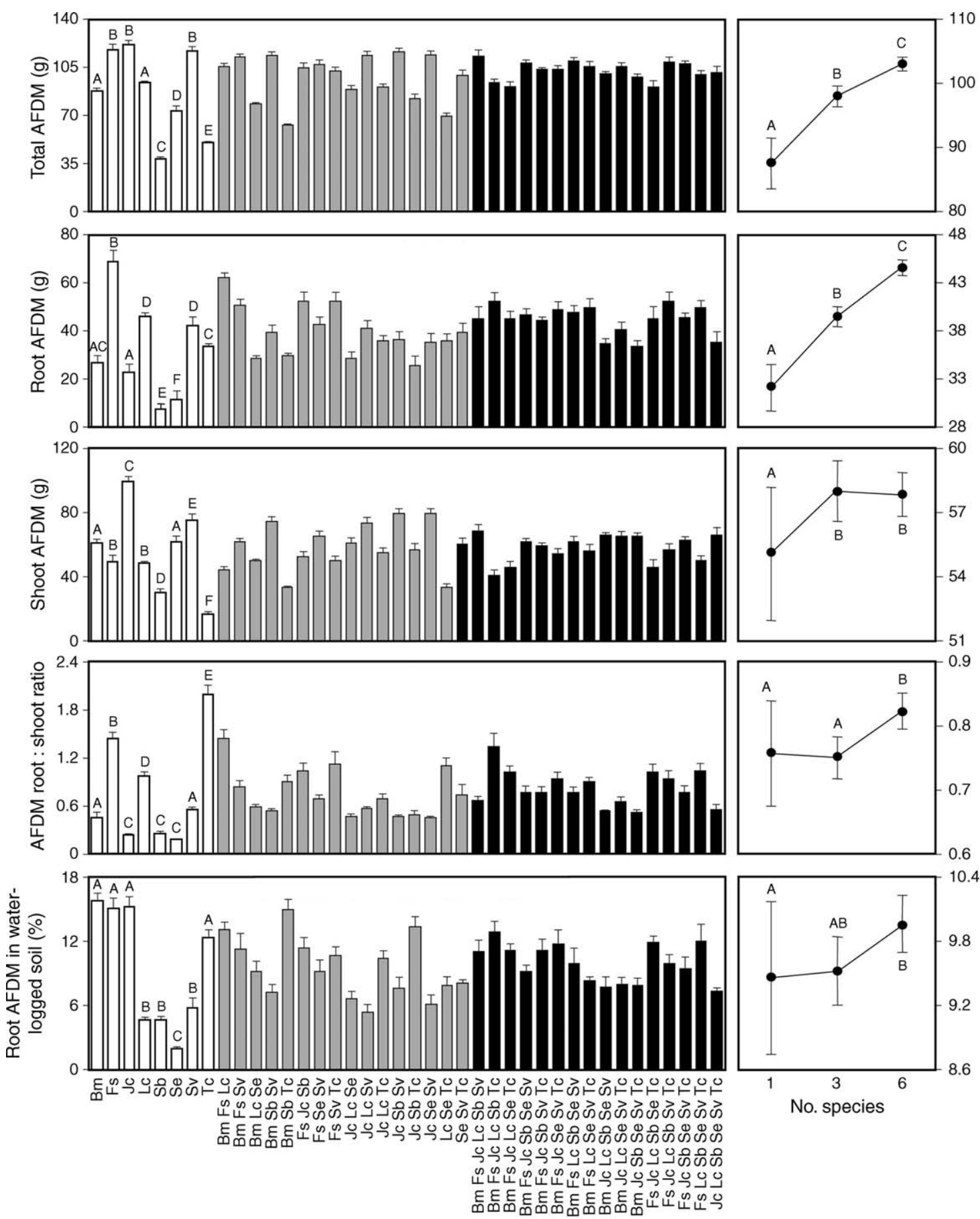

Assemblage

FIG. 1. Individual assemblage means (left panel) and contrast means among assemblages with different numbers of species (right panel) for AFDM variables. Assemblage means are shown for eight species in solo (clear bars), 16 randomly drawn trios (gray bars), and 16 randomly drawn sextets (black bars). Species codes are in Table 1. Significant differences among solo means (based on Tukey multiple comparisons) and among contrast means (based on post hoc multiple comparisons with Dunn-Sidak adjusted alpha $=0.01695$ ) are indicated by different letters. Error bars represent $\pm \mathrm{SE}$. 

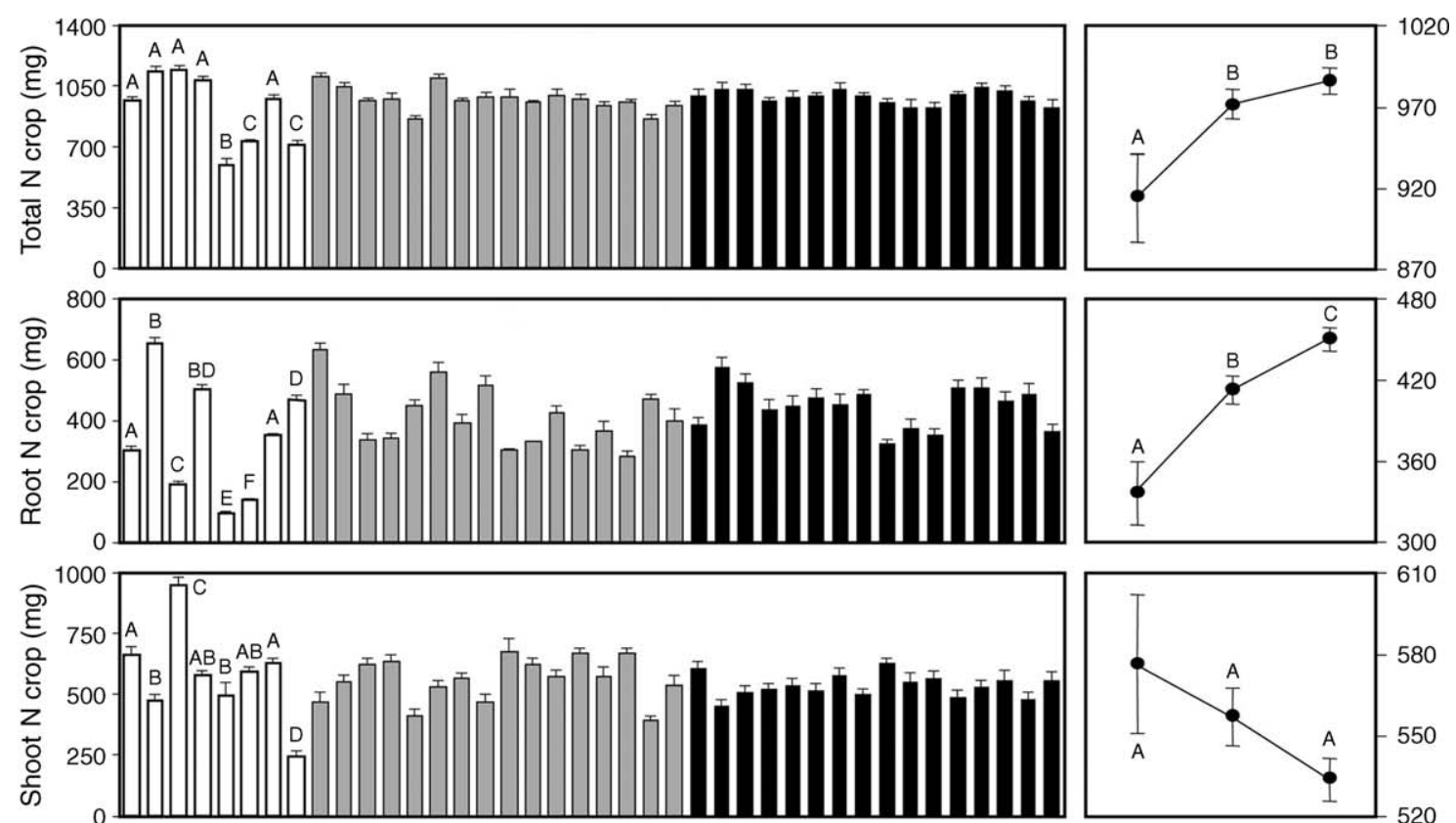

을

\section{(}

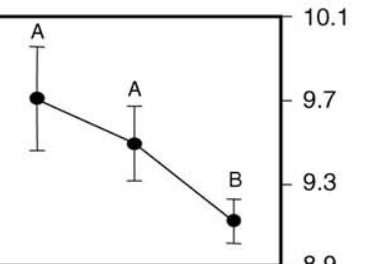

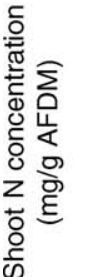

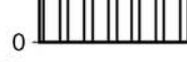

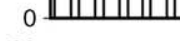

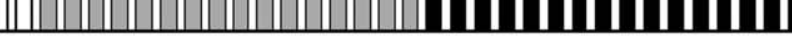
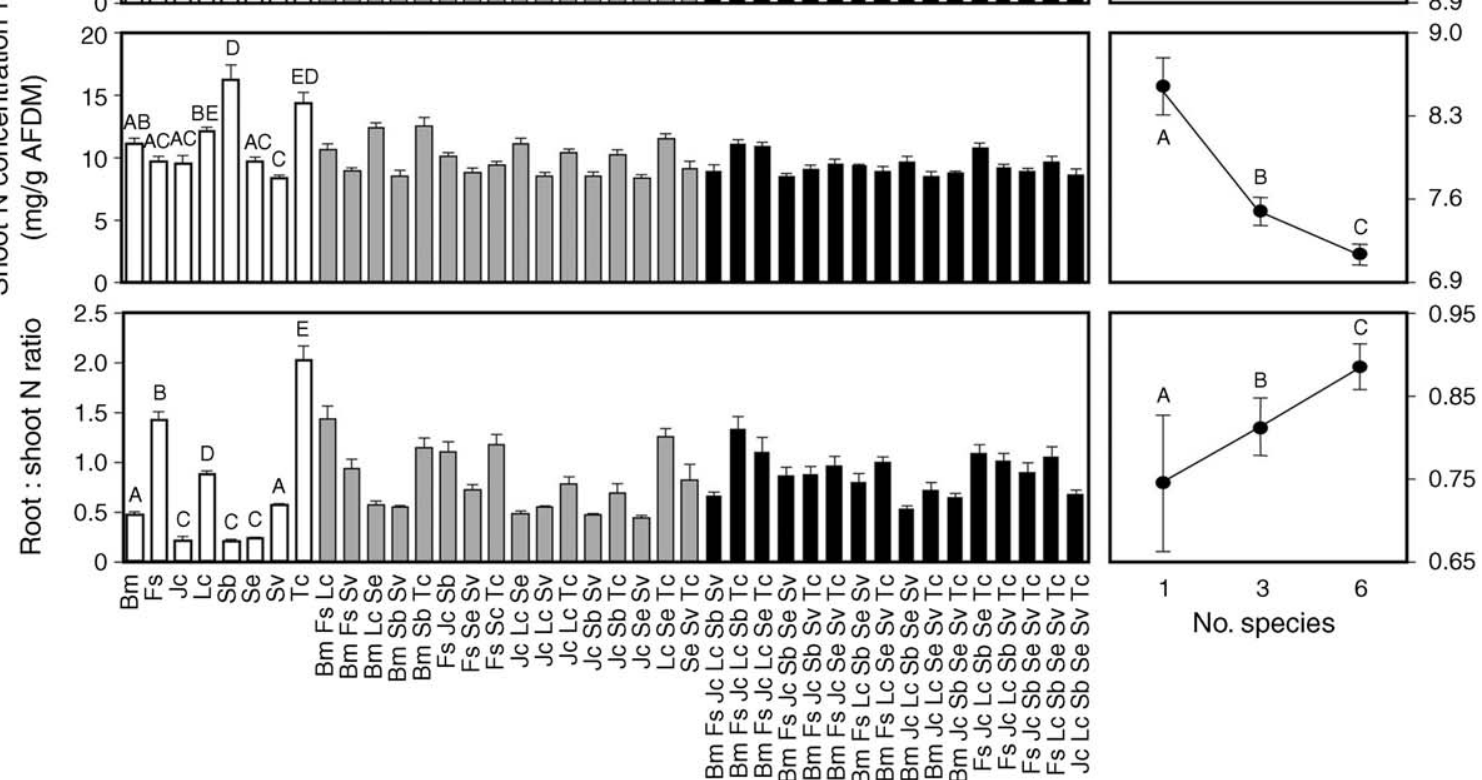

Assemblage

FIG. 2. Individual assemblage means (left panel) and contrast means among assemblages with different numbers of species (right panel) for $\mathrm{N}$ crop and $\mathrm{N}$ concentration variables. Assemblage means are shown for eight species in solo (clear bars), 16 randomly drawn trios (gray bars), and 16 randomly drawn sextets (black bars). Species codes are in Table 1. Significant differences among solo means (based on Tukey multiple comparisons) and among contrast means (based on post hoc multiple comparisons with Dunn-Sidak adjusted alpha $=0.01695$ ) are indicated by different letters. Error bars represent \pm SE. 
TAble 5. Mean $D_{\mathrm{T}}, D_{\max }, D_{\mathrm{dom}}, D_{\mathrm{CE}}$, and $D_{\mathrm{SE}}$ deviations for trios and sextets.

\begin{tabular}{|c|c|c|c|c|}
\hline Parameters & Trios & Sextets & $F$ & $P$ \\
\hline \multicolumn{5}{|l|}{$D_{\mathrm{T}}$} \\
\hline Total AFDM & 0.095 & 0.168 & 27.999 & $<0.00$ \\
\hline Root AFDM & 0.250 & 0.395 & 25.474 & $<0.00$ \\
\hline Shoot AFDM & 0.014 & 0.038 & 1.532 & 0.217 \\
\hline AFDM R:S ratio & 0.065 & 0.106 & 1.145 & 0.28 \\
\hline Deep roots $(\%) \dagger$ & 0.077 & 0.025 & 2.007 & 0.158 \\
\hline Total N crop & 0.062 & 0.080 & 2.277 & 0.13 \\
\hline Root N crop & 0.124 & 0.144 & 0.658 & 0.41 \\
\hline Shoot N crop & -0.043 & -0.076 & 3.351 & 0.06 \\
\hline Root $\mathrm{N}$ concentration & -0.009 & -0.066 & 17.133 & $<0.00$ \\
\hline Shoot $\mathrm{N}$ concentration & -0.095 & -0.165 & 33.160 & $<0.00$ \\
\hline N R:S ratio & 0.173 & 0.215 & 0.917 & \\
\hline \multicolumn{5}{|l|}{$D_{\max }$} \\
\hline Total AFDM & -0.161 & -0.184 & 4.329 & 0.03 \\
\hline Root AFDM & -0.202 & -0.274 & 16.416 & $<0.00$ \\
\hline Shoot AFDM & -0.284 & -0.378 & 50.655 & $<0.00$ \\
\hline AFDM R:S ratio & -0.402 & -0.537 & 47.370 & $<0.00$ \\
\hline Deep roots $(\%) \dagger$ & -0.371 & -0.393 & 1.005 & 0.31 \\
\hline Total N crop & -0.115 & -0.152 & 13.020 & $<0.00$ \\
\hline Root N crop & -0.250 & -0.316 & 12.077 & $<0.00$ \\
\hline Shoot N crop & -0.267 & -0.389 & 80.065 & $<0.00$ \\
\hline Root $\mathrm{N}$ concentration & -0.169 & -0.274 & 75.185 & $<0.00$ \\
\hline Shoot $\mathrm{N}$ concentration & -0.244 & -0.401 & 146.60 & $<0.00$ \\
\hline N R:S ratio & -0.347 & -0.490 & 37.921 & $<0.00$ \\
\hline \multicolumn{5}{|l|}{$D_{\text {dom }}$} \\
\hline Shoot AFDM & -0.162 & -0.170 & 0.141 & 0.70 \\
\hline Shoot N crop & -0.057 & -0.092 & 1.270 & 0.16 \\
\hline Shoot $\mathrm{N}$ concentration & -0.199 & -0.299 & 45.342 & $<0.00$ \\
\hline \multicolumn{5}{|l|}{$D_{\mathrm{CE}}$} \\
\hline Shoot AFDM & -0.019 & -0.031 & 0.553 & 0.45 \\
\hline Shoot N crop & 0.007 & -0.045 & 2.534 & 0.11 \\
\hline Shoot $\mathrm{N}$ concentration & -0.001 & -0.028 & 4.422 & 0.03 \\
\hline \multicolumn{5}{|l|}{$D_{\mathrm{SE}}$} \\
\hline Shoot AFDM & 0.033 & 0.069 & 7.174 & 0.00 \\
\hline Shoot N crop & -0.049 & -0.031 & 0.119 & 0.73 \\
\hline Shoot $N$ concentration & -0.096 & -0.137 & 19.853 & $<0.00$ \\
\hline
\end{tabular}

Notes: Values in bold differ significantly from zero; values $>$ 0 are italic. Determinations are based on $95 \%$ CI $(n=16)$. Also reported are $F$ and $P$ values of the contrasts $(\mathrm{df}=1)$ between trios and sextets from a randomized block ANOVA $(n=256$, error $\mathrm{df}=217$ ). Because roots could not be assessed by species, $D_{\text {dom, }} D_{\mathrm{CE}}$, and $D_{\mathrm{SE}}$ deviations are only reported on shoot characteristics.

$\dagger$ Percentage of roots in waterlogged soil strata.

species with mature seed at harvest. The three most productive species (Fs, Jc, and Sv) tied with Se for the lowest shoot $\mathrm{N}$ concentration.

\section{Responses to increasing species richness}

As expected based on our earlier field experiment, sextets generally outperformed solos, with trios intermediate (hypothesis 2). Biodiversity effects were clear for 10 of the 11 response variables, with eight variables increasing with richness (Figs. 1 and 2; Appendix A). Total AFDM and total $\mathrm{N}$ crop responded similarly, with trios significantly greater than solos, despite root and shoot $\mathrm{N}$ concentrations decreasing with richness. The proportion of AFDM and $\mathrm{N}$ crop belowground increased from solos to sextets, as did the percentage of roots in waterlogged soil. Three of the 11 response variables contradicted our hypothesis that sextets would outperform solos; shoot $\mathrm{N}$ crop did not differ with richness, while root and shoot $\mathrm{N}$ concentrations decreased with richness.

We also examined richness effects in assemblages without the regional dominant Sv, and found a similar pattern of response (Appendix B). Total and root AFDM, AFDM root: shoot ratio, percentage of roots in waterlogged soil, root $\mathrm{N}$ concentrations, and $\mathrm{N}$ root: shoot ratio increased with higher levels of richness, i.e., sextets $>$ trios $>$ solos. Total $\mathrm{N}$ crop increased from solos to multispecies assemblages, sextets $>$ solos for shoot $\mathrm{N}$ concentration and trios $>$ solos for $\operatorname{root} \mathrm{N}$ concentration.

\section{Variations within replicates of an assemblage}

Replicates often varied greatly within an assemblage, such that some effects might not have been detected during statistical testing. Standard deviations for three attributes (shoot AFDM, shoot $\mathrm{N}$ crop, and shoot $\mathrm{N}$ concentration; Appendices C-E) were often 10-20\% of their respective means, and standard deviations for biodiversity effects (NBE, CE, and SE) often exceeded the index mean. Deviations also varied in sign. Even though we later explain enhanced biomass or $\mathrm{N}$ accumulation as due to SE or CE, a significant finding is that replicates of trios and sextets were quite variable, making it difficult to characterize biodiversity effects even within a specific assemblage.

\section{Transgressive and non-transgressive overyielding}

Patterns of non-transgressive overyielding due to the net of all biodiversity effects (NBE) varied across the 11 response variables and between trios and sextets $\left(D_{\mathrm{T}}\right.$ : Tables 3 and 5, Appendix F). While most $D_{\mathrm{T}}$ deviations in total AFDM were positive due to the strongly positive deviations in root AFDM, the response among shoots was more idiosyncratic with relatively few positive or negative deviations. There were fewer positive $D_{\mathrm{T}}$ deviations for all measures of $\mathrm{N}$ crop, primarily due to the many negative deviations in root and shoot $\mathrm{N}$ concentrations (Tables 3 and 5; Appendix F). However, there was only one negative deviation in root $\mathrm{N}$ crop, with positive deviations associated with strong positive deviations in root AFDM. There were eight negative and no positive deviations in shoot $\mathrm{N}$ crop. For total $\mathrm{N}$ crop, there were 13 positive and one negative deviation, the exception being an assemblage with negative deviations in both root and shoot $\mathrm{N}$ concentration coupled with no deviation in total AFDM. The positive deviations in $\mathrm{N}$ root: shoot ratio were generally associated with positive deviations in AFDM root: shoot ratio.

Mean $D_{\mathrm{T}}$ deviations for trios and sextets in total and root AFDM, total $\mathrm{N}$ crop, and $\mathrm{N}$ root : shoot ratio were all positive, and positive for sextets in root $\mathrm{N}$ crop. No deviation was observed among trios or sextets in shoot AFDM, AFDM root:shoot ratio, or percentage of 
roots in waterlogged soil, or for trios in root and shoot $\mathrm{N}$ crop and root $\mathrm{N}$ concentrations. Mean deviations were negative for root $\mathrm{N}$ concentrations among sextets, and for shoot $\mathrm{N}$ concentration among trios and sextets. Mean deviations in root and total AFDM were significantly greater for sextets than trios. Conversely, mean deviations in root and shoot $\mathrm{N}$ concentration were significantly less for sextets than trios.

We found no evidence of transgressive overyielding relative to the highest yielding solo of an assemblage species $\left(D_{\max }\right)$, with the majority of trios and all but one sextet transgressively underyielding on all variables (Table 3, Appendix G). On average, trios and sextets both transgressively underyielded, with deviations among sextets more negative than trios in 10 of the 11 attributes assessed (Table 5). The only differences between trio and sextet deviations that were not significant were in the percentage of roots in waterlogged soil.

Nor were there any positive deviations in our analysis of transgressive overyielding relative to the solo yield of the assemblage dominant $\left(D_{\text {dom }}\right.$, shoot characteristics only; Table 3, Appendix G). However in sharp contrast to the results of the $D_{\max }$ deviation analysis, shoot AFDM and shoot $\mathrm{N}$ crop did not consistently underyield. Only eight assemblages transgressively underyielded in shoot $\mathrm{N}$ crop, and each of these was associated with transgressive underyielding in both shoot AFDM and shoot $\mathrm{N}$ concentration. The trio and sextet $D_{\text {dom }}$ deviation means for shoot AFDM and shoot $\mathrm{N}$ concentration were both negative, while only the mean sextet deviation in shoot $\mathrm{N}$ crop was negative (Table 5).

\section{Overyielding of species within assemblages}

Some species were consistent within AFDM, N crop, and shoot $\mathrm{N}$ concentration (overyielding, underyielding, or not significant), although the response may not have been the same across these variables $\left(D_{i j} ; D_{i}\right.$ reported in Appendices $\mathrm{H}-\mathbf{J}$ ). The response of other species was more idiosyncratic and appeared to be related to its biotic environment, i.e., the other species with which it did or did not co-occur. With one exception among the 32 assemblages and three response variables, we found only one overyielding species per treatment. In one sextet, Fs and Tc both overyielded in shoot $\mathrm{N}$ crop.

The regional dominant $\mathrm{Sv}$ strongly overyielded in shoot AFDM and shoot $\mathrm{N}$ crop, dominating the assemblages in which it occurred (Appendices $\mathrm{H}$ and I). In assemblages without $\mathrm{Sv}$, the overyielding dominant was Fs, Jc, Lc, or Tc. Sv did not dominate in shoot $\mathrm{N}$ concentration, which was primarily dominated by Tc, or by Lc or Bm in assemblages in which Tc did not occur (Appendix J). The two short-lived species ( $\mathrm{Sb}$ and $\mathrm{Se}$ ) and the dominant solo in shoot AFDM (Jc) underyielded in nearly all assemblages. Fs and Tc either overyielded or yielded as expected in nearly all assemblages. Bm underyielded in shoot AFDM and shoot $\mathrm{N}$ crop, but along with $\mathrm{Sv}$, yielded as expected in shoot $\mathrm{N}$ concentration.

\section{Selection and complementarity effects and deviations}

Using the deviation of individual species yields from expected based on their yields in solo on shoot characteristics $\left(D_{i j} ; D_{i}\right.$ reported in Appendices $\left.\mathrm{H}-\mathrm{J}\right)$, we were able to decompose the NBE into complementarity effects (CE) and selection effects (SE; Loreau and Hector 2001). In support of our fourth hypothesis, we found highly variable SE and $\mathrm{CE}$ both within and among assemblages (Appendices $\mathrm{C}-\mathrm{E}$ ). Despite this variation, a large portion of the aboveground NBE was clearly due to $\mathrm{SE}$, or the covariation between species performance in solo and their relative yield in trios or sextets.

From the $D_{i j}$ deviations on shoot characteristics, we were also able to calculate the deviations in NBE due to $\mathrm{CE}$ and to $\mathrm{SE}\left(D_{\mathrm{CE}}\right.$ and $D_{\mathrm{SE}}$ : modified from Loreau and Hector 2001). Few $D_{\mathrm{CE}}$ deviations were significant, and all but one were negative (Tables 3 and 6). Of the 14 positive $D_{\mathrm{SE}}$ deviations, all but one were associated with strongly positive $D_{\mathrm{Sv}}\left(D_{i}\right.$ for $\left.\mathrm{Sv}\right)$ deviations and nonsignificant $D_{\mathrm{CE}}$ deviations (Appendices $\mathrm{H}-\mathrm{J}$ ). None of these was associated with negative $D_{T}$ deviations.

For shoot AFDM (Table 6), there were four negative $D_{\mathrm{CE}}$ deviations, with five negative $D_{\mathrm{SE}}$ and 12 positive $D_{\mathrm{SE}}$ deviations. All negative $D_{\mathrm{T}}$ deviations occurred in assemblages without $\mathrm{Sv}$ and were associated with negative $D_{\mathrm{CE}}$ and/or negative $D_{\mathrm{SE}}$ deviations, while all positive $D_{\mathrm{T}}$ deviations occurred in assemblages with $\mathrm{Sv}$ and were associated with positive $D_{\mathrm{SE}}$ deviations (Appendix H). Other species had positive $D_{i}$ deviations (Fs, Jc, Lc, and Tc), all in assemblages without Sv, and none was associated with positive $D_{\mathrm{CE}}, D_{\mathrm{SE}}$, or $D_{\mathrm{T}}$ deviations. Although the mean NBE was not significant for trios or sextets (Table 5), the mean sextet $\mathrm{CE}$ was negative, and the mean sextet SE was positive and significantly greater than trios.

For shoot $\mathrm{N}$ crop (Table 6), there were only two significant $D_{\mathrm{CE}}$ deviations, both were negative and among sextets. One trio had a positive $D_{\mathrm{SE}}$ deviation, and six trios and four sextets had negative $D_{\mathrm{SE}}$ deviations. Negative $D_{\mathrm{SE}}$ deviations for shoot $\mathrm{N}$ crop were each associated with one of four overyielding species (Appendix I). The mean NBE was negatively significant among sextets, while the mean SE was negatively significant among trios (Table 5). Differences among trio and sextet NBE, CE, or SE means were not significant.

For shoot $\mathrm{N}$ concentration (Table 6), we found only one positive $D_{\mathrm{CE}}$ deviation among trios and two negative $D_{\mathrm{CE}}$ deviations each for trios and sextets. Only one trio had a positive $D_{\mathrm{SE}}$ deviation, while 27 assemblages had negative $D_{\mathrm{SE}}$ deviations. Of these 28 assemblages with significant SE, only 12 were associated with an overyielding species (nine positive $D_{\mathrm{Tc}}$ and three positive $D_{\mathrm{Lc}}$; Appendix J). Due to the strongly negative $\mathrm{SE}$ and relative lack of $\mathrm{CE}$, mean $\mathrm{NBE}$ and 
TABLE 6. Deviations in yield for shoot characteristics due to biodiversity effects for each trio and sextet.

\begin{tabular}{|c|c|c|c|c|c|c|}
\hline \multirow[b]{2}{*}{ Assemblage } & \multicolumn{2}{|c|}{ Shoot AFDM } & \multicolumn{2}{|c|}{ Shoot $N$ crop } & \multicolumn{2}{|c|}{ Shoot $\mathrm{N}$ concentration } \\
\hline & $D_{\mathrm{CE}}$ & $D_{\mathrm{SE}}$ & $D_{\mathrm{CE}}$ & $D_{\mathrm{SE}}$ & $D_{\mathrm{CE}}$ & $D_{\mathrm{SE}}$ \\
\hline Bm Fs Lc & -0.111 & -0.046 & -0.102 & -0.069 & 0.017 & -0.043 \\
\hline $\mathrm{Bm}$ Fs Sv & -0.034 & 0.047 & -0.003 & -0.028 & 0.038 & -0.088 \\
\hline $\mathrm{Bm} \mathrm{Lc} \mathrm{Se}$ & -0.101 & -0.017 & 0.021 & -0.002 & 0.142 & 0.000 \\
\hline $\mathrm{Bm} \mathrm{Sb} \mathrm{Sv}$ & 0.040 & 0.311 & 0.021 & 0.047 & -0.065 & -0.203 \\
\hline $\mathrm{Bm} \mathrm{Sb} \mathrm{Tc}$ & 0.006 & -0.073 & 0.110 & -0.176 & 0.043 & -0.092 \\
\hline Fs Jc Sb & -0.076 & -0.033 & -0.045 & -0.123 & -0.044 & -0.093 \\
\hline Fs Se Sv & -0.032 & 0.088 & -0.037 & 0.046 & -0.044 & -0.001 \\
\hline Fs Sv Tc & -0.013 & 0.076 & 0.008 & 0.034 & 0.041 & $-\mathbf{0 . 1 7 0}$ \\
\hline Jc Lc Se & -0.070 & -0.053 & -0.002 & -0.043 & 0.062 & -0.004 \\
\hline Jc Lc Sv & 0.010 & -0.022 & -0.018 & -0.115 & -0.053 & -0.093 \\
\hline Jc Lc Tc & -0.002 & 0.017 & 0.038 & -0.069 & 0.059 & -0.186 \\
\hline $\mathrm{Jc} \mathrm{Sb} \mathrm{Sv}$ & 0.055 & 0.120 & 0.037 & -0.066 & -0.146 & -0.106 \\
\hline $\mathrm{Jc} \mathrm{Sb} \mathrm{Tc}$ & -0.024 & 0.189 & 0.037 & -0.019 & 0.044 & -0.276 \\
\hline Jc Se Sv & 0.043 & -0.037 & 0.029 & -0.105 & -0.100 & 0.022 \\
\hline $\mathrm{Lc} \mathrm{Se} \mathrm{Tc}$ & -0.015 & -0.192 & -0.041 & -0.141 & 0.007 & -0.040 \\
\hline Se Sv Tc & 0.018 & 0.153 & 0.054 & 0.042 & 0.016 & -0.162 \\
\hline Bm Fs Jc Lc Sb Sv & 0.004 & 0.128 & -0.015 & -0.032 & -0.059 & -0.141 \\
\hline Bm Fs Jc Lc Sb Tc & -0.169 & -0.020 & -0.111 & -0.086 & 0.054 & -0.136 \\
\hline Bm Fs Jc Lc Se Tc & -0.126 & -0.053 & -0.041 & -0.091 & 0.083 & $-\mathbf{0 . 0 8 0}$ \\
\hline $\mathrm{Bm}$ Fs Jc Sb Se Sv & -0.052 & 0.040 & -0.105 & -0.063 & -0.140 & -0.066 \\
\hline Bm Fs Jc Sb Sv Tc & -0.020 & 0.092 & -0.013 & -0.052 & -0.070 & -0.142 \\
\hline Bm Fs Jc Se Sv Tc & -0.047 & -0.044 & -0.008 & -0.119 & 0.062 & -0.148 \\
\hline $\mathrm{Bm}$ Fs Lc Sb Se Sv & -0.032 & 0.186 & -0.008 & 0.032 & -0.037 & $-\mathbf{0 . 1 2 5}$ \\
\hline Bm Fs Lc Se Sv Tc & -0.007 & 0.090 & -0.034 & -0.018 & 0.009 & -0.179 \\
\hline $\mathrm{Bm}$ Jc Lc Sb Se Sv & -0.048 & 0.101 & -0.024 & -0.008 & -0.016 & -0.117 \\
\hline $\mathrm{Bm} \mathrm{Jc} \mathrm{Lc} \mathrm{Se} \mathrm{Sv} \mathrm{Tc}$ & 0.026 & 0.058 & -0.043 & -0.056 & -0.025 & $-\mathbf{0 . 1 8 8}$ \\
\hline $\mathrm{Bm} \mathrm{Jc} \mathrm{Sb} \mathrm{Se} \mathrm{Sv} \mathrm{Tc}$ & -0.013 & 0.148 & -0.026 & -0.021 & -0.068 & -0.173 \\
\hline Fs Jc Lc Sb Se Tc & -0.048 & -0.056 & 0.009 & -0.132 & -0.009 & -0.086 \\
\hline Fs Jc Lc Sb Sv Tc & 0.004 & 0.069 & 0.011 & -0.069 & -0.014 & -0.189 \\
\hline Fs Jc Sb Se Sv Tc & 0.058 & 0.069 & 0.072 & -0.082 & -0.090 & -0.122 \\
\hline Fs Lc Sb Se Sv Tc & -0.034 & 0.108 & 0.003 & -0.044 & -0.021 & -0.144 \\
\hline Jc Lc Sb Se Sv Tc & 0.015 & 0.183 & -0.029 & -0.009 & -0.106 & $-\mathbf{0 . 1 5 7}$ \\
\hline
\end{tabular}

Notes: Key to abbreviations: $D_{\mathrm{CE}}$, deviation due to CE ( $D$ when species evenness is constant); $D_{\mathrm{SE}}$, deviation due to SE (modified from Loreau and Hector [2001]). Deviations in bold differ significantly from zero; values $>0$ are italic. Determinations are based on $95 \%$ CI $(n=8)$.

mean SE were negative for both trios and sextets (Table 5). Differences between trio and sextet NBE, $\mathrm{CE}$, and $\mathrm{SE}$ were all significant, with sextets more negative than trios.

\section{Effects of four target species on trios}

Trios had lower overlap in composition and higher variability in performance than sextets (because trios had fewer species in common than did sextets). Further analysis of trios lent additional support for hypothesis 3; i.e., the characteristics of individual species strongly influenced how assemblages performed. The function of trios was strongly influenced by the identity of component species when contrasting assemblages with and without one of four target species (Fs, Jc, Sv, or Tc; defined in Methods; Figs. 3 and 4, Table 7). The effect of target species was generally related to their performance in solo; e.g., Fs, Jc, and Sv tended to increase AFDM, while Tc increased $\mathrm{N}$ concentrations.

Assemblages with Fs had greater root and total AFDM, AFDM root: shoot ratios, percentage of roots in waterlogged soil, root and total $\mathrm{N}$ crop, and $\mathrm{N}$ root: shoot ratios. Assemblages with $\mathrm{Jc}$ had lower root AFDM, AFDM root: shoot ratios, root $\mathrm{N}$ crop, and $\mathrm{N}$ root: shoot ratios; and greater shoot and total AFDM, and shoot $\mathrm{N}$ crop. Assemblages with $\mathrm{Sv}$ had more root, shoot, and total AFDM; and lower percentage of roots in waterlogged soil, root and shoot $\mathrm{N}$ concentrations, and $\mathrm{N}$ root: shoot ratios. Assemblages with $\mathrm{Tc}$ had lower shoot and total AFDM, percentage of roots in waterlogged soil, root $\mathrm{N}$ crop; and greater root and shoot $\mathrm{N}$ concentrations, and $\mathrm{N}$ root : shoot ratio.

Trios with these four species performed either better or worse than those without. To determine if the performance of the target species itself was responsible for the increased or decreased yield in trios, we correlated target species yield on assemblage yield for shoot AFDM and shoot $\mathrm{N}$ crop. In trios in which $\mathrm{Sv}$ occurred, it directly accounted for most of the shoot AFDM and shoot $\mathrm{N}$ crop (Figs. 5 and 6). In contrast, in trios in which Tc occurred, shoot AFDM or shoot $\mathrm{N}$ crop decreased as Tc shoot AFDM or shoot $\mathrm{N}$ crop increased. No impact of Fs or Jc shoot AFDM or $\mathrm{N}$ crop was detected on trio shoot AFDM or shoot $\mathrm{N}$ crop.

\section{Discussion}

Plant assemblages with more species or functional groups typically have enhanced ecosystem functioning relative to monotypes (Balvanera et al. 2006, Cardinale et al. 2006, Worm et al. 2006); thus, much of the current 

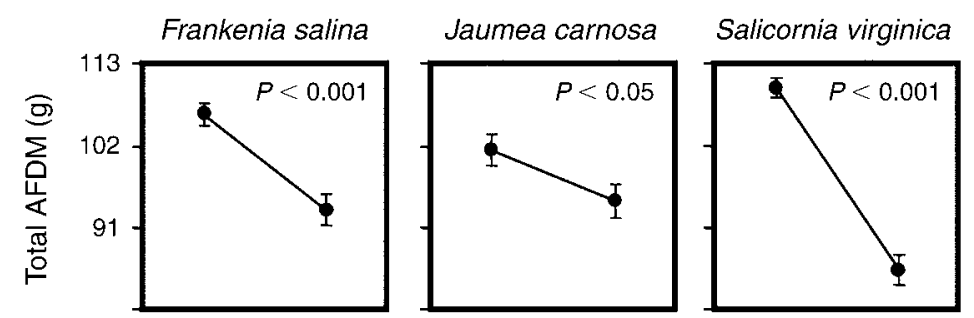

Triglochin concinna
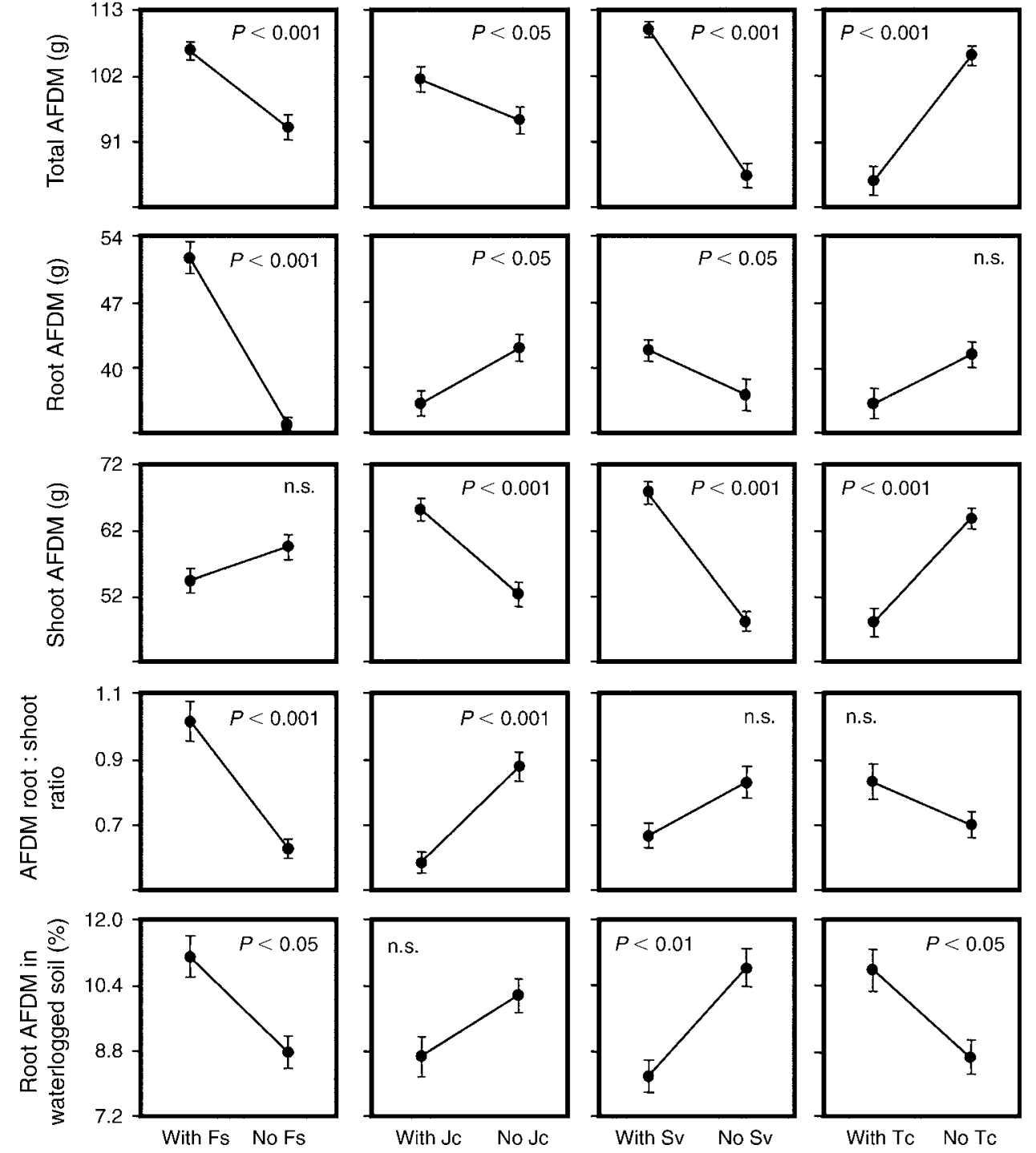

FIG. 3. AFDM responses for trios with and without four target species. The panels show post hoc contrasts $(\mathrm{df}=1)$ between trios with and without Sv, Tc, Fs, or Jc for root AFDM, shoot AFDM, total AFDM, AFDM root: shoot ratio, and the percentage of roots utilizing waterlogged soil strata. Significance was determined with the Scheffé adjusted $F$ statistic to reduce family-wise error. Species codes are in Table 1; n.s., not significant.

debate is whether responses are due to selection effects (covariance between solo yields and $\Delta \mathrm{RY}$ ) and/or complementarity effects (e.g., resource partitioning, facilitation, interference and/or suppression; Hector 1998, Loreau 1998, Loreau and Hector 2001, Petchey 2003, Fox 2005, Hooper et al. 2005). Our study contributes to the debate by exploring variation among replicates $(n=$ 8) of each assemblage, assessing a broad range of functions (11 response variables), quantifying complementarity effects (CE) and selection effects (SE) on shoot response variables, evaluating influences of individual species in detail, and comparing outcomes of greenhouse and field experiments that tested the same 32 assemblages. Because these species exhibit unique character sets with low trait redundancy (Sullivan and Zedler 1999), we considered functional diversity among species rather than among groups (Petchey and Gaston 2006).

\section{Eight halophytes had unique functional profiles}

The eight halophytes of the southern California salt marsh plain exhibited individuality in this experiment, in support of our first hypothesis. That is, each had a unique profile based on 11 attributes, and no species was maximal in all attributes (Figs. 1 and 2). Even though the congeners, $\mathrm{Sb}$ and $\mathrm{Sv}$, seemed redundant in an earlier one-year experiment (Sullivan and Zedler 1999), 


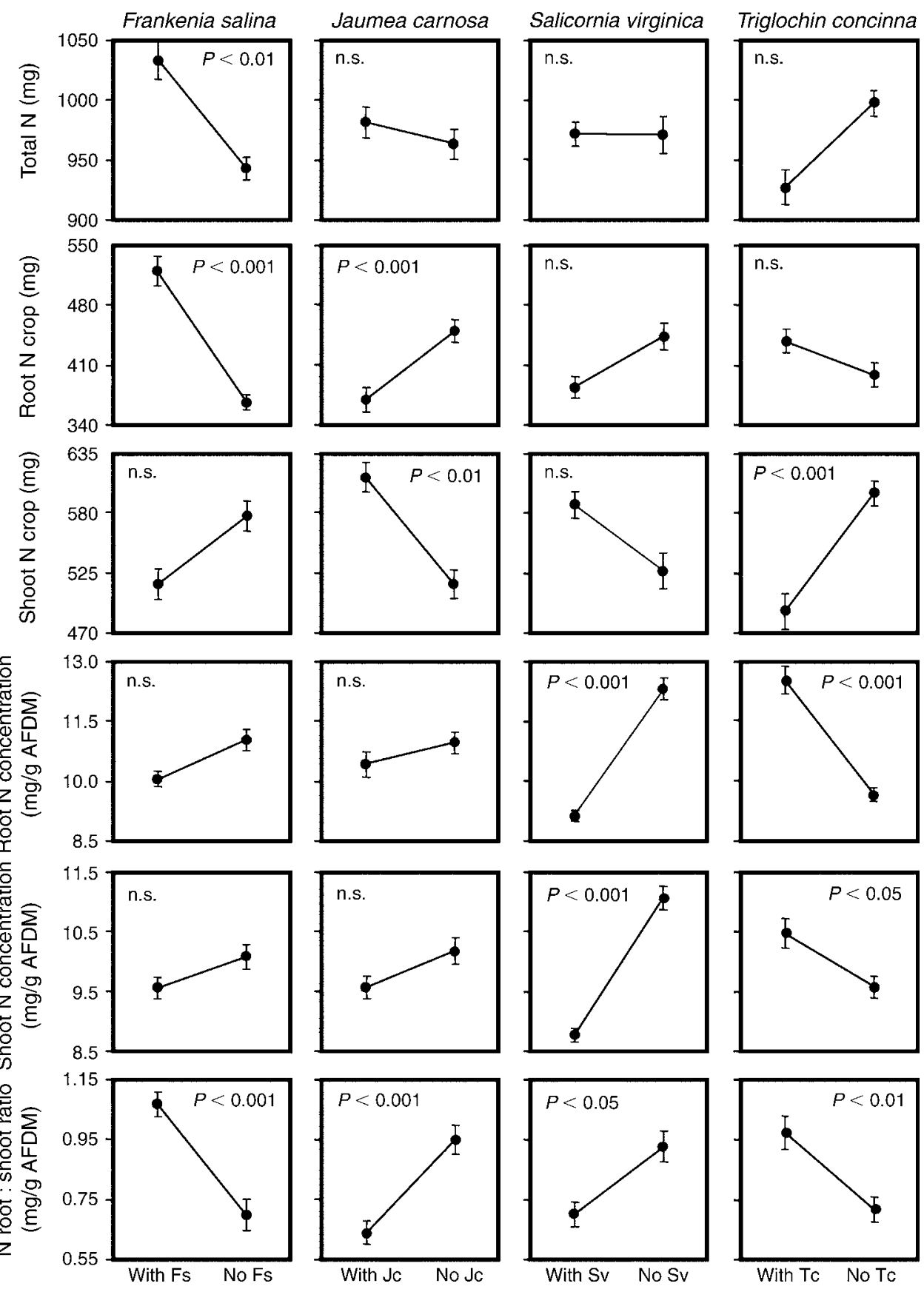

FIG. 4. Responses of $\mathrm{N}$ crop and $\mathrm{N}$ concentrations for trios with and without four target species. The panels show post hoc contrasts $(\mathrm{df}=1)$ between trios with and with no $\mathrm{Sv}, \mathrm{Tc}, \mathrm{Fs}$, or $\mathrm{Jc}$ for root $\mathrm{N}$ concentration $(\mathrm{mg} / \mathrm{g}$ AFDM), shoot $\mathrm{N}$ concentration $(\mathrm{mg} / \mathrm{g}$ AFDM), root N, shoot N, total N, and N root: shoot ratio. Significance was determined with the Scheffé adjusted $F$ statistic to reduce family-wise error. Species codes are in Table 1; n.s., not significant.

they differed significantly in every attribute assessed at two years (see Results). More similar were Sv, Jc, and Fs, which produced the most ash-free biomass (and dry mass; data not shown), had similar root and shoot $\mathrm{N}$ concentrations, and similar total $\mathrm{N}$ crops. But of these three, the succulent $(\mathrm{Jc})$ and non-succulent (Fs) were more similar to one another than were the two succulents (Jc and Sv). As cautioned earlier (Sullivan and Zedler 1999), functional differences need to be measured, not extrapolated from morphology.

Other attributes became important in interpreting these species' persistence in the field experiment. These were life history ( $\mathrm{Sb}$ is an annual; Se is short-lived; Tc has ephemeral shoots but perennial roots; the rest are 
TABLE 7. Contrasts between trios with and without four target species (Fs, Jc, Sv, or Tc) evaluated with the Scheffé test for multiple contrasts.

\begin{tabular}{|c|c|c|}
\hline Parameters & $S$ & $P$ \\
\hline \multicolumn{3}{|l|}{$F \mathrm{~s}$} \\
\hline Total AFDM & 8.97 & $<0.001$ \\
\hline Root AFDM & 14.177 & $<0.001$ \\
\hline Shoot AFDM & 2.129 & ns \\
\hline AFDM R:S ratio & 9.367 & $<0.001$ \\
\hline Deep roots $(\%) \dagger$ & 5.299 & $<0.05$ \\
\hline Total N crop & 5.822 & $<0.01$ \\
\hline Root N crop & 11.734 & $<0.001$ \\
\hline Shoot N crop & -3.312 & ns \\
\hline Root $\mathrm{N}$ concentration & -4.324 & ns \\
\hline Shoot $\mathrm{N}$ concentration & -2.381 & ns \\
\hline N R:S ratio & 8.014 & $<0.001$ \\
\hline \multicolumn{3}{|l|}{$\mathrm{Jc}$} \\
\hline Total AFDM & 5.285 & $<0.05$ \\
\hline Root AFDM & -5.226 & $<0.05$ \\
\hline Shoot AFDM & 8.836 & $<0.001$ \\
\hline AFDM R:S ratio & 7.683 & $<0.001$ \\
\hline Deep roots $(\%) \dagger$ & -3.791 & ns \\
\hline Total N crop & 1.071 & ns \\
\hline Root N crop & -7.228 & $<0.001$ \\
\hline Shoot N crop & 6.282 & $<0.01$ \\
\hline Root N concentration & -3.453 & ns \\
\hline Shoot $\mathrm{N}$ concentration & -3.821 & ns \\
\hline N R:S ratio & -7.256 & $<0.001$ \\
\hline \multicolumn{3}{|l|}{$\mathrm{Sv}$} \\
\hline Total AFDM & 17.275 & $<0.001$ \\
\hline Root AFDM & 5.575 & $<0.05$ \\
\hline Shoot AFDM & 12.918 & 0.001 \\
\hline AFDM R:S ratio & -4.258 & ns \\
\hline Deep roots $(\%) \dagger$ & -6.241 & $<0.01$ \\
\hline Total $\mathrm{N}$ crop & 0.281 & ns \\
\hline Root N crop & -4.999 & ns \\
\hline Shoot N crop & 4.207 & ns \\
\hline Root $\mathrm{N}$ concentration & -18.608 & $<0.001$ \\
\hline Shoot $\mathrm{N}$ concentration & -13.749 & $<0.001$ \\
\hline N R:S ratio & -5.175 & $<0.05$ \\
\hline \multicolumn{3}{|l|}{$\mathrm{Tc}$} \\
\hline Total AFDM & 14.737 & $<0.001$ \\
\hline Root AFDM & -4.797 & ns \\
\hline Shoot AFDM & 10.825 & $<0.001$ \\
\hline AFDM R:S ratio & 3.38 & ns \\
\hline Deep roots $(\%) \dagger$ & 5.173 & $<0.05$ \\
\hline Total N crop & -4.677 & ns \\
\hline Root N crop & 4.07 & ns \\
\hline Shoot N crop & -7.046 & $<0.001$ \\
\hline Root $\mathrm{N}$ concentration & 15.557 & $<0.001$ \\
\hline Shoot $\mathrm{N}$ concentration & 5.565 & $<0.05$ \\
\hline N R:S ratio & 5.94 & $<0.01$ \\
\hline
\end{tabular}

Notes: The Scheffé test statistic $(S)$ was evaluated against the Scheffe critical value $\left(S_{\alpha}\right) . S_{\alpha}$ is the square root of the product of the factor $\mathrm{df}$ (assemblage) and the critical value of $F$ at a given alpha with $15 \mathrm{df}$ (assemblage) and $105 \mathrm{df}$ (error) from the randomized block ANOVA of trios with "assemblage" and "block" as factors. $S$ values in bold indicate significant differences between trios with and without target species. All variables were transformed as noted in Appendix A. For $P \leq$ $0.05, F_{15,105}=1.76, S=5.138$; for $P \leq 0.01, F_{15,105}=2.21, S=\overline{5}$. 758 ; for $P \leq 0.001, F_{15,105}=2.82, S=6.504$; ns, not significant. $\dagger$ Percentage of roots in waterlogged soil strata.

evergreen perennial forbs or subshrubs), potential to recruit from seeds $(\mathrm{Sv}, \mathrm{Sb}$, and $\mathrm{Se}$ recruit readily; the others do so very rarely), reproductive mode (only $\mathrm{Sb}$ and Se must recruit seedlings to persist), growth form
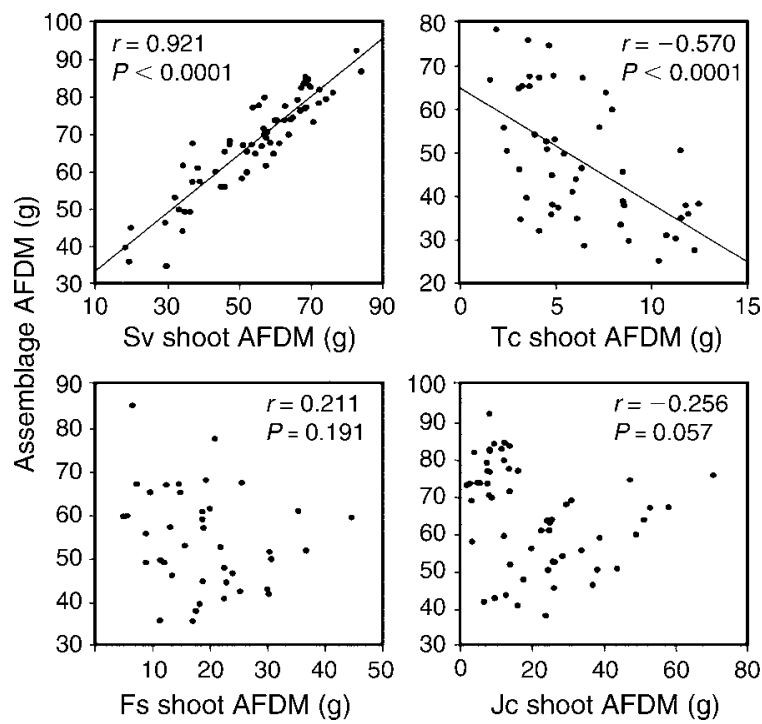

FIG. 5. Effect of a target species' shoot AFDM on assemblage shoot AFDM in trios where the target species was present. Sv, Tc, Fs, and Jc are defined in Table 1.

(Sv, Fs, Se, and $\mathrm{Sb}$ are upright; $\mathrm{Jc}$ and $\mathrm{Bm}$ are trailing with long runners; Lc forms a basal rosette; Tc forms tufts; Fs is non-succulent; the rest are succulent) (Zedler et al. 2001, Lindig-Cisneros and Zedler 2002). While some might consider the salt marsh a single functional group of salt-tolerant species, we disagree, just as we would not consider a desert community with annual, perennial, succulent, and non-succulent species to be a single drought-tolerant functional group.
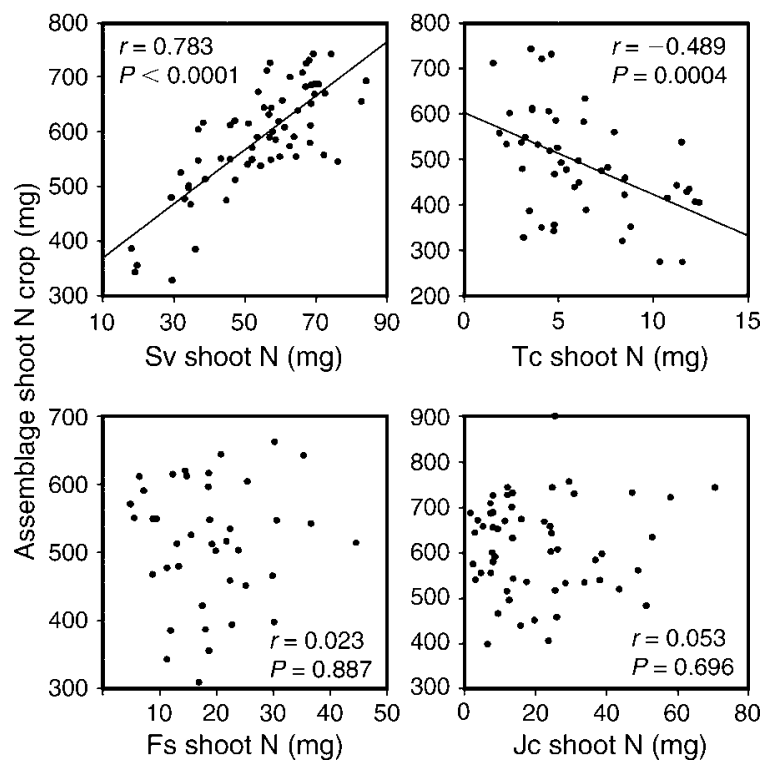

FIG. 6. Effect of a target species' shoot $\mathrm{N}$ crop on assemblage shoot $\mathrm{N}$ crop in trios where the target species was present. Sv, Tc, Fs, and Jc are defined in Table 1. 


\section{Richness effects}

Our eight-species salt marsh system was no exception to the general rule that species-rich assemblages enhance function (Hooper et al. 2005, Balvanera et al. 2006), as eight of the 11 response variables were significantly greater for sextets than solos. Richness effects (NBE) were observed in all five measures of biomass plus two measures of $\mathrm{N}$ accumulation (root and total $\mathrm{N}$ crop) and one measure of allocation (root:shoot $\mathrm{N}$ crop), supporting our second hypothesis. Nitrogen concentration among roots and shoots decreased with richness because biomass increased more than $\mathrm{N}$ crop. Shoot $\mathrm{N}$ crop did not respond because assemblages were allocating more $\mathrm{N}$ belowground with increasing richness, indicated by greater root:shoot $\mathrm{N}$ ratios. This also suggests a saturating effect without an increase in shoot biomass, shoot $\mathrm{N}$, or total $\mathrm{N}$ between trios and sextets. These findings illustrated a change in function with increasing richness, but they do not reveal the underlying mechanisms responsible, nor do they allow us to detect richness effects where assemblage performance potentially resulted from both positive and negative species interactions.

\section{Overyielding}

Relative to the weighted average of member species grown solo (NBE indicated as $D_{\mathrm{T}}$ ), assemblages strongly overyielded in total and root biomass and $\mathrm{N}$ crop, while they generally underyielded in root and shoot $\mathrm{N}$ concentrations and shoot $\mathrm{N}$ crop. The mean response among trios or sextets reflected these trends, with sextets overyielding more strongly in root and total biomass, and underyielding more strongly in root and shoot $\mathrm{N}$ concentration, a pattern reflected in the results of the richness effects analysis. These trends were not significant where assemblage response was more idiosyncratically related to assemblage composition (Appendix F), and in particular, the presence or absence of particular species, e.g., Sv in shoot biomass. Although others have suggested that such idiosyncratic effects become more likely as richness is reduced (Naeem et al. 1995), this trend was observed among some characteristics at the highest level of richness examined due to strong sampling effects (Fridley 2001, Petchey 2003), a conclusion further supported by the species effects analyses (Figs. 3 and 4).

Our analyses of transgressive overyielding ( $D_{\max }$ and $D_{\text {dom }}$ ) provided no evidence that overyielding due to NBE resulted from positive species interactions, although this did not preclude such interactions being masked by sampling or SE (Loreau 1998, Hooper et al. 2005). Transgressive underyielding in sextets exceeded that of trios in 11 of the 14 mean comparisons, suggesting sampling effects due to the greater probability of including a species who might dominate or negatively influence the yield of the entire assemblage. $D_{\max }$ deviations were overwhelmingly negative because the highest yielding solos generally exceeded the yields of trios and sextets, while performing poorly in mixture due to sampling or SE. Many $D_{\text {dom }}$ deviations were also negative, while others were neither negative nor positive because the net of all species interactions resulted in assemblage yields equaling that of the dominant solo.

It seems intuitive that the relative strength and balance among species interactions and their effects on assemblage performance may differ among experiments due to the response variable measured and the biotic and abiotic environments in which it is measured. In this experiment, resource partitioning or other positive species interactions were not strong enough to result in positive $D_{\text {dom }}$ or $D_{\max }$ deviations, while others have found assemblage yields often exceeding that of the dominant solo within a given system (e.g., Hector et al. 2002). Neutral $D_{\text {dom }}$ deviations in shoot $\mathrm{N}$ crop occurred in $75 \%$ of trios and sextets, suggesting that the availability of $\mathrm{N}$ may also have influenced species interactions and ultimately limited the yield of solos, trios, and sextets alike (Spaekova and Leps 2001, Hooper and Dukes 2004), while others have found that low fertility resulted in a strong underyielding response (Fridley 2002).

\section{Selection and complementarity effects (SE, CE)}

A unique understanding of assemblage overyielding patterns across response variables was possible through the deviations in yield due to CE and SE: $D_{\mathrm{CE}}$ and $D_{\mathrm{SE}}$. This allowed us to compare the relative strength of $\mathrm{CE}$ and SE within and among assemblages in three shoot characteristics differing in scale: AFDM, N crop, and $\mathrm{N}$ concentration. We found that selection was the dominant effect responsible for the NBE (relating to our third hypothesis), and negative $\mathrm{SE}$ more common on $\mathrm{N}$ characteristics due to the strong influence of species with lower than average yields in solo. Others have reported differences in the relative balance between $\mathrm{CE}$ and SE, with CE most often stronger than SE, and where it was measured, the balance between them fluctuating through time (Dukes 2001, Leps et al. 2001, Polley et al. 2003, van Ruijven and Berendse 2003, Hooper and Dukes 2004, Caldeira et al. 2005, Roscher et al. 2005, Spehn et al. 2005). Here, despite species characteristics thought to promote resource niche partitioning (Hooper et al. 2005, Spehn et al. 2005), CE were rarely significant and contributed little to the NBE. The relative strength and direction of either CE or SE differed with the attribute being assessed, supporting our fourth hypothesis.

With replicated assemblages, it became apparent that the dominance of a species yielding above or below average in solo does not always result in a predictable SE. Positive SE are predicted to occur when species with higher than average solos dominate mixtures (Lambers et al. 2004, Caldeira et al. 2005, Spehn et al. 2005). However the presence of an overyielding species with higher than average solo yield (a positive sampling effect) did not result in positive $\mathrm{SE}$ in 43 of 56 assemblages across the three variables. The 13 positive 
SE were all associated with strongly positive $D_{\mathrm{Sv}}$ deviations, although other positive $D_{\mathrm{Sv}}$ deviations did not result in positive SE. Conversely, negative SE are thought to occur when species yielding less than the average in solo dominate mixtures, but nine of 16 assemblages dominated by species yielding less than average in solo did not result in negative SE. Most negative SE occurred in assemblages where the NBE was negative and there were no $\mathrm{CE}$; i.e., the negative effects of diversity were entirely due to selection. Negative SE also occurred in assemblages in which no species overyielded, indicating that negative SE do not require overyielding by a species yielding less than average in solo.

These findings do not lend themselves to ready interpretation, and they suggest that, even when the contribution of individual species is available, the mechanisms underlying diversity effects may not be clear. For example, the regional dominant Sv strongly overyielded in both shoot AFDM and N crop (positive $D_{\mathrm{Sv}}$ deviations) in all but one of 42 assemblages, resulting in strong underyielding among five of the species co-occurring with $\mathrm{Sv}$, one of which (Jc) yielded significantly greater than $\mathrm{Sv}$ in solo. However two species did not underyield ( $\mathrm{Fs}$ and $\mathrm{Tc}$ ), but either overyielded or more commonly yielded as expected. Although positive $\mathrm{CE}$ were not measured, this suggests Fs and Tc had access to sufficient resources despite the dominance of Sv. That both species had high AFDM and $\mathrm{N}$ root : shoot ratios, and greater use of the waterlogged soil strata $(>>\mathrm{Sv})$ further suggests that they were able to avoid competition with $\mathrm{Sv}$ through resource niche partitioning belowground, positive complementarity that did not show up in the analysis of shoot AFDM or $\mathrm{N}$ crop. This interpretation was only possible through the investigation of species allocation above- and belowground; simply evaluating aboveground productivity would not have identified the mechanisms underlying diversity effects. Detailed knowledge of individual species' resource allocation and utilization of niche space, such as in this experiment, enhanced our understanding of the mechanisms underlying diversity effects.

\section{Impacts of target species on trios}

Our analyses of target species provided new insights into how individual species influence biodiversity effects. Four species strongly influenced trio performance, but not in the same way (Fig. 3). Highly productive species (Sv, Fs, Jc) led to highly productive trios, but one species (Tc) actually reduced trio biomass. Despite its low biomass, Tc appeared to inhibit the growth of other species through its superior ability to take up N. The species with superior root production (Fs) produced assemblages with exceptionally high root biomass, and two species that sent many roots into waterlogged soil (Fs, Tc) produced trios that performed similarly. But one pattern was not so straightforward. A species with high shoot biomass $(\mathrm{Jc})$ increased trio shoot biomass, but otherwise, it was almost always outcompeted by another species in the trio. Our explanation draws on additional observations of growth form. Jc is a trailing succulent that never grows tall, so its leaves are usually in the shade of its neighbors.

The roles of individual species were further supported by analyses of individual deviations, which are unique to our study. $D_{i j}$ identified a major overyielding species (Sv), which strongly overyielded in shoot biomass and $\mathrm{N}$ crop and was responsible for most of the shoot biomass and $\mathrm{N}$ crop of the trios in which it occurred. $D_{i j}$ showed that another productive species (Jc) strongly underyielded in shoot biomass and $\mathrm{N}$ crop, indicating its poor competitive ability in mixture, a context-specific sampling effect (Dukes 2001).

Because $D_{i j}$ identified a major overyielding species (Sv), we expected the biodiversity effect to be weak in assemblages that lacked this species. However, the biodiversity effect not only persisted in assemblages without that species, it was stronger. The analysis of individual species showed why - another high performer (Fs) became the overyielder in the absence of the top performer.

Although our analysis of CE did not attribute NBE to positive species interactions (niche partitioning or facilitation), the $D_{i j}$ analyses indicated that two species (Fs, Tc) were unaffected by the strongest performer (Sv). Thus, some resource space could have been used differently among these species (e.g., Sv sent fewer roots into waterlogged soil than Fs and Tc). We suggest that such $\mathrm{CE}$ were masked by the overwhelmingly negative responses of other species to the dominant Sv.

\section{Variables that affect net biodiversity effects (NBE)}

Our fifth hypothesis, that the strength and magnitude of all effects would vary with the attribute assessed, was more limited in scope than indicated by the results of our detailed evaluations. Not only did NBE differ with the response variable, but also with the assemblage tested and even among replicates within an assemblage (Figs. 1 and 2).

Differences among response variables suggest using caution in extrapolating NBE from a single process (such as aboveground productivity). For example, the assumption that shoot biomass represents total plant productivity, food availability, habitat structure for wildlife, or overall ecosystem functioning might not be justifiable. To allow generalization, response variables need to match the functions of interest (Giller et al. 2004). In our greenhouse experiment, NBE depended on the response variable assessed; e.g., $\mathrm{N}$ crop increased, but root and shoot $\mathrm{N}$ concentration decreased. Thus, our interpretation of how roots improve soil or trap nutrients would be positive if the response variable were $\mathrm{N}$ crop but negative if based on root $\mathrm{N}$ concentration. Similarly, in our parallel field experiment (same 32 assemblages), shoot biomass and canopy layering 
increased with richness, while canopy cover and canopy height did not (Keer and Zedler 2002). In this case, our evaluation of support for an endangered bird (Belding's Savannah Sparrow, Passerculus sandwichensis beldingi) would be positive if extrapolated from biomass but neutral if extrapolated from height. The height response could be the more critical one, because male birds perch on tall stems to defend their nesting territories. In many southern California salt marshes, Sv monotypes provide tall canopies and nesting habitat, suggesting that plant diversity might not be critical to this endangered species.

Differences among assemblages helped us understand species' roles in ecosystem functioning. For example, one species $(\mathrm{Tc})$ readily accumulated $\mathrm{N}$ belowground but yielded the lowest shoot biomass and never dominated an assemblage. A more productive species (Sv) had a higher $\mathrm{N}$ crop but lower concentrations of $\mathrm{N}$ in both roots and shoots. If $\mathrm{N}$ were more limiting than in our experiment, Tc might be the superior competitor. In fact, Morzaria-Luna (2004) showed that Tc could reduce $\mathrm{Sv}$ biomass when $\mathrm{N}$ was limiting and that $\mathrm{Sv}$ outgrew Tc when she added $\mathrm{N}$ in her greenhouse experiment. Others have found that outcomes can reverse, for example, when some disturbance intervenes. Cardinale and Palmer (2002) showed that a periodic disturbance prevented dominance by a productive animal species; Mulder et al. (2001) found a richness effect on moss productivity when assemblages (1-32 species) were exposed to drought, but not under constant conditions; and Pfisterer and Schmid (2002) showed that drought favored species-poor assemblages in a grassland experiment (1-32 species) measuring vascular plant biomass.

Last, outcomes varied among replicates within an assemblage. We found variation in magnitude and sign of both effects and deviations, as well as in combinations of positive and negative selection and interaction effects. We know of no other results that show such wide variations within naturally occurring assemblages of plants that began as near equals, i.e., one young seedling per species in sextets, two per species in trios). Such variations could come about given slightly different starting conditions, such as a more aggressive genotype or a slightly larger seedling (analogous to different sequences of introduction investigated by Fukami and Morin 2003).

Conclusions about biodiversity effects on ecosystem functioning under spatially heterogeneous and dynamic natural conditions should acknowledge that outcomes can differ with many variables. We recommend (1) assessing multiple functions; (2) replicating assemblages to help represent the variability that occurs in nature and to allow the testing of significance of CE and SE at the assemblage level; and (3) testing a high proportion of assemblages at each species-richness level. As noted by others, the community considered is also a key factor (as in 171 studies reviewed by Mittelbach et al. [2001] and 103 studies reviewed by Balvanera et al. [2006]).

\section{Similar outcomes in greenhouse and field experiments}

Our test of 32 assemblages in the greenhouse matched those in our salt marsh restoration site (Callaway et al. 2003), even though each experimental approach has unique limitations (Duffy et al. 2001, Cameron 2002, Walker and Langridge 2002, Balvanera et al. 2006). In both, sextet biomass and $\mathrm{N}$ crop were significantly higher than solos, with trios intermediate (Callaway et al. 2003). The long-term outcome, however, was assessed only in the field. After nine years (in November 2005), we documented increased dominance by two productive species ( $\mathrm{Sv}$ and Jc; Zedler and West, in press) and loss of the short-lived species ( $\mathrm{Sb}, \mathrm{Se}$ ) and the low biomass producer with ephemeral shoots (Tc). In 2005, average richness was 2.8 species $/ 0.25-\mathrm{m}^{2}$ plot, compared to the historical maximum for Tijuana Estuary of 4.2 species/plot (Zedler and West, in press). A system that was planted with near-equal numbers of eight species might have sustained evenness; instead, it lost richness over time.

While strong positive $\mathrm{CE}$ would have predicted the persistence of species-rich plots in the salt marsh, the nine-year decline in diversity is better explained by a preponderance of SE. The two species that became dominant in the field (Sv, 96\% frequency, 49\% cover; Jc, $61 \%$ frequency, $29 \%$ cover) were top performers in the greenhouse. Sv contributed up to $75 \%$ of the total AFDM in trios, even though it did not perform highest in any attribute when grown solo. Sv overyielded in total shoot biomass at the expense of its neighbors. In addition, it was the tallest perennial (average height 22 $\mathrm{cm}$ in pots), and in the field it sustained the tallest, evergreen canopy (C. L. Bonin and J. B. Zedler, unpublished data). High productivity, tall canopy, and longevity explain Sv's ultimate dominance as a monotype (few neighbors) in the experimental salt marsh, in another Californian salt marsh (Ibarra-Obando and Poumian-Tapia 1991), and in the region (Zedler et al. 2001). In contrast to Sv, Jc had many associates in the field, and in the greenhouse it mostly underyielded and invested its shoot biomass in long, flexible runners, rather than height $(14 \mathrm{~cm})$. These behaviors suggest $\mathrm{CE}$, with Jc facilitating other species, including Fs with its short canopy $(12 \mathrm{~cm})$ and third highest cover $(8 \%)$. The decline in diversity in the field, however, supports the finding that SE outnumber CE.

Our findings of strong SE in California salt marsh vegetation support those in serpentine grasslands of California (Hooper and Vitousek 1997), European grasslands (Leps et al. 2001, Kahmen et al. 2006), and aquatic ecosystems (Duffy et al. 2001, O'Connor and Crowe 2005, Cardinale et al. 2006). In other cases, strong $\mathrm{CE}$ have been indicated. For example, Caldeira et al. (2001) found high water use in species-rich mixtures. Multispecies assemblages can enhance overall functioning by utilizing resources in different places (e.g., soil strata, canopy strata) or at different times, although 
Stevens and Carson (2001) did not find evidence for phenological complementarity.

\section{Predictions for biodiversity conservation}

Lack of consistency in the literature led Srivastava and Vellend (2005) to conclude that BEF research has "little practical advice for conservation managers." In contrast, the results of meta-analyses by Worm et al. (2006), Balvanera et al. (2006), and Cardinale et al. (2006) overwhelmingly indicated that ecosystem services decline with biodiversity loss but that various factors influence the effect size. In particular, the loss of the most productive species reduces productivity, via the sampling effect (Cardinale et al. 2006). If biodiversityecosystem function theory is to assist in conservation efforts, we need to examine changes in function with realistic examples of species loss (Schmid and Hector 2004). In our salt marsh experiment, richness declined to 2.8 species $/ 0.25 \mathrm{~m}^{2}$ (Zedler and West, in press), similar to trios in this experiment. If species were lost randomly, a shift from sextets to trios should have reduced total biomass, reduced root biomass, reduced root $\mathrm{N}$ crop, increased shoot and root $\mathrm{N}$ concentrations, and reduced root: shoot $\mathrm{N}$ ratio. But one cannot assume a random loss of species and assemblages (Huston et al. 2000, Schwartz et al. 2000, Giller et al. 2004). We argue that species loss in the field experiment was nonrandom because the three species that were most productive in the greenhouse became most abundant; Sv, Jc, and Fs ranked first, second, and third in both frequency and cover (Zedler and West, in press). The species pool had only two short-lived species ( $\mathrm{Sb}, \mathrm{Se}$ ), and both dropped out of the system, further indicating that diversity loss was nonrandom.

Did we lose function with nonrandom loss of diversity? The data for Sv, Jc, and Fs suggest that we did not, although none of our random trios was SvJcFs; however, at least two of those species were present in six trios, all of which were highly productive (above-average total AFDM). With productive species persisting, the field experiment did not likely experience a reduction in productivity over its first decade. In fact, the ability of Sv, Jc, and Fs to sustain high productivity both as solos and in assemblages suggests a cause-effect feedback loop, i.e., more productivity by Sv, Jc, and Fs leads to greater dominance. Also, because SE tended to outnumber $\mathrm{CE}$ and most $\mathrm{CE}$ were negative in the greenhouse, we expect further diversity loss in the field over the next decade. These predictions follow from our use of environmental conditions that were similar to those in nature, assemblage sizes (solos, trios, sextets) that actually occur at small spatial scales (MorzariaLuna et al. 2004), and the natural pool of eight species. Balvanera et al. (2006) found that experiments with fewer than 10 species yield weaker biodiversity effects, and our salt marsh pool naturally falls below that threshold. Our study revealed strong selection effects, with three species (Sv, Jc, and Fs) being highly productive alone and in assemblages.

Although our data do not provide strong support for functional consequences of diversity loss, there is risk in extrapolating to all ecosystem functions. From other studies, we know that the three most productive species differ in microsite use (e.g., waterlogged soil subdues $\mathrm{Sv}$ but sustains $\mathrm{Sb}$; A. K. Varty and J. B. Zedler, unpublished data), seed banks ( $\mathrm{Sv}$ and Tc form persistent seed banks; Morzaria-Luna and Zedler 2007), and recruitment ability $(\mathrm{Sv}, \mathrm{Sb}$, and Se readily recruited seedlings when the restoration site had ample open space, but others did not; Lindig-Cisneros and Zedler 2001). Thus, loss of short-lived species that readily recruit from seed banks should diminish resilience in salt marshes that lack these species. A key to predicting functional loss is measuring the critical response variables. While productivity could be sustained by a monotype of a productive species, the community's capacity to recover from disturbances might well have declined. Thus, we agree with Worm et al. (2006), Balvanera et al. (2006), and Cardinale et al. (2006) that managers should preserve biodiversity as a precautionary measure for sustaining ecosystem functions. In the southern California salt marsh, this means restoring microtopographic variability to recover plant species that require specific microsites plus collecting and storing seed to reintroduce species that rarely recruit.

\section{AcKNowledgments}

We thank Earth Island Institute and the National Science Foundation (DEB 96-19875, DEB 0212005) for funding the research and the U.S. Fish and Wildlife Service for the greenhouse at San Diego State University. We are indebted to the many affiliates of the Pacific Estuarine Research Laboratory who helped maintain and harvest the microcosms and to Lisa Thurn for analyzing thousands of nitrogen samples. Comments from two anonymous reviewers were very helpful and are much appreciated.

\section{Literature Cited}

Aarssen, L. W. 1997. High productivity in grassland ecosystems: effected by species diversity or productive species? Oikos 80:183-184.

Balvanera, P., A. B. Pfisterer, N. Buchmann, J. S. He, T. Nakashizuka, D. Raffaelli, and B. Schmid. 2006. Quantifying the evidence for biodiversity effects on ecosystem functioning and services. Ecology Letters 9:1146-1156.

Caldeira, M. C., A. Hector, M. Loreau, and J. S. Pereira. 2005. Species richness, temporal variability and resistance of biomass production in a mediterranean grassland. Oikos 110:115-123.

Caldeira, M. C., R. J. Ryel, J. H. Lawton, and J. S. Pereira. 2001. Mechanisms of positive biodiversity-production relationships: insights provided by $\delta^{13} \mathrm{C}$ analysis in experimental Portuguese grassland plots. Ecology Letters 4:439-443.

Callaway, J. C., G. Sullivan, and J. B. Zedler. 2003. Species-rich plantings increase biomass and nitrogen accumulation in a wetland restoration experiment. Ecological Applications 13: 1626-1639.

Cameron, T. 2002. The year of the 'diversity-ecosystem function' debate. Trends in Ecology and Evolution 17:495496. 
Cardinale, B. J., and M. A. Palmer. 2002. Disturbance moderates biodiversity ecosystem function relationships: evidence from suspension feeding caddisflies in stream mesocosms. Ecology 83:1915-1927.

Cardinale, B. J., M. A. Palmer, and S. L. Collins. 2002. Species diversity enhances ecosystem functioning through interspecific facilitation. Nature 415:426-429.

Cardinale, B. J., D. S. Srivastava, J. E. Duffy, J. P. Wright, A. L. Downing, M. Sankaran, and C. Jouseau. 2006. Effects of biodiversity on the functioning of trophic groups and ecosystems. Nature 443:989-992.

Chapin, F. S., E.-D. Schulze, and H. A. Mooney. 1992. Biodiversity and ecosystem processes. Trends in Ecology and Evolution 7:107-108.

Cottingham, K. L., B. L. Brown, and J. T. Lennon. 2001. Biodiversity may regulate the temporal variability of ecological systems. Ecology Letters 4:72-85.

Darwin, C. 1859. The origin of species by means of natural selection. Sixth edition. D. Appleton, New York, New York, USA.

Diaz, S., and M. Cabido. 2001. Vive la difference: plant functional diversity matters to ecosystem processes. Trends in Ecology and Evolution. 16:646-655.

Duffy, J. E., K. S. Macdonald, J. M. Rhode, and J. D. Parker. 2001. Grazer diversity, functional redundancy, and productivity in seagrass beds: an experimental test. Ecology 82: $2417-2434$.

Dukes, J. S. 2001. Productivity and complementarity in grassland microcosms of varying diversity. Oikos 94:468-480.

Dukes, J. S. 2002. Species composition and diversity affect grassland susceptibility and response to invasion. Ecological Applications 12:602-617.

Ewel, J. J., M. J. Mazzarino, and C. W. Berish. 1991. Tropical soil fertility changes under monocultures and successional communities of different structure. Ecological Applications 1:289-302.

Fargione, J. E., and D. Tilman. 2005. Diversity decreases invasion via both sampling and complementarity effects. Ecology Letters 8:604-611.

Fox, J. W. 2005. Interpreting the 'selection effect' of biodiversity on ecosystem function. Ecology Letters 8:846-856.

Fridley, J. D. 2001. The influence of species diversity on ecosystem productivity: how, where, and why? Oikos 93:514526.

Fridley, J. D. 2002. Resource availability dominates and alters the relationship between species diversity and ecosystem productivity in experimental plant communities. Oecologia 132:271-277.

Fukami, T., and P. J. Morin. 2003. Productivity-biodiversity relationships depend on the history of community assembly. Nature 424:423-426.

Fukami, T., S. Naeem, and D. A. Wardle. 2001. On similarity among local communities in biodiversity experiments. Oikos 95:340-348.

Giller, P., et al. 2004. Biodiversity effects on ecosystem functioning: emerging issues and their experimental test in aquatic environments. Oikos 104:423-436.

Hector, A. 1998. The effect of diversity on productivity: detecting the role of species complementarity. Oikos 82:597-599.

Hector, A., E. Bazeley-White, M. Loreau, S. J. Otway, and B. Schmid. 2002. Overyielding in grassland communities: testing the sampling effect hypothesis with replicated biodiversity experiments. Ecology Letters 5:502-511.

Hector, A., K. Dobson, B. A. Minns, E. Bazeley-White, and J. H. Lawton. 2001. Community diversity and invasion resistance: an experimental test in a grassland ecosystem and a review of comparable studies. Ecological Research 16:819-831.

Hector, A., et al. 1999. Plant diversity and productivity experiments in European grasslands. Science 286:1123-1127.

Hector, A., et al. 2000. Response: no consistent effect of plant diversity on productivity. Science $289: 1255 \mathrm{a}$.
Hooper, D. U. 1998. The role of complementarity and competition in ecosystem responses to variation in plant diversity. Ecology 79:704-719.

Hooper, D. U., et al. 2005. Effects of biodiversity on ecosystem functioning: a consensus of current knowledge. Ecological Monographs 75:3-35.

Hooper, D. U., and J. S. Dukes. 2004. Overyielding among plant functional groups in a long-term experiment. Ecology Letters 7:95-105.

Hooper, D. U., and P. M. Vitousek. 1997. The effects of plant composition and diversity on ecosystem processes. Science 277:1302-1305.

Huston, M. A. 1997. Hidden treatments in ecological experiments: re-evaluating the ecosystem function of biodiversity. Oecologia 110:449-460.

Huston, M. A., et al. 2000. Technical comment: no consistent effect of plant diversity on productivity. Science 289:1255a.

Ibarra-Obando, S. E., and M. Poumian-Tapia. 1991. The effect of tidal exclusion on salt marsh vegetation in Baja California, México. Wetlands Ecology and Management 1:131-148.

Kahmen, A., C. Renker, S. B. Unsicker, and N. Buchmann. 2006. Niche complementarity for nitrogen: an explanation for the biodiversity and ecosystem functioning relationship? Ecology 87:1244-1255.

Keer, G. H., and J. B. Zedler. 2002. Salt marsh canopy architecture differs with the number and composition of species. Ecological Applications 12:456-473.

Kennedy, T. A., S. Naeem, K. M. Howe, J. M. H. Knops, D. Tilman, and P. Reich. 2002. Biodiversity as a barrier to ecological invasion. Nature 417:636-638.

Knops, J. M. H., et al. 1999. Effects of plant species richness on invasion dynamics, disease outbreaks, insect abundances and diversity. Ecology Letters 2:286-293.

Kokkoris, G. D., V. A. A. Jansen, M. Loreau, and A. Y. Troumbis. 2002. Variability in interaction strength and implications for biodiversity. Journal of Animal Ecology 71:362-371.

Lambers, J. H. R., W. S. Harpole, D. Tilman, J. Knops, and P. B. Reich. 2004. Mechanisms responsible for the positive diversity-productivity relationship in Minnesota grasslands. Ecology Letters 7:661-668.

Lamont, B. B. 1995. Testing the effect of ecosystem composition/structure on its functioning. Oikos 74:283-295.

Leps, J., et al. 2001. Separating the chance effect from other diversity effects in the functioning of plant communities. Oikos 92:123-134.

Lindig-Cisneros, R., and J. B. Zedler. 2002. Halophyte recruitment in a salt marsh restoration site. Estuaries 26: $1174-1183$.

Loreau, M. 1998. Separating sampling and other effects in biodiversity experiments. Oikos 82:600-602.

Loreau, M., A. Downing, M. C. Emmerson, A. Gonzalez, J. Hughes, P. Inchausti, J. Joshi, J. Norberg, and O. Sala. 2002. A new look at the relationship between diversity and stability. Pages 79-91 in M. Loreau, S. Naeem, and P. Inchausti, editors. Biodiversity and ecosystem functioning: synthesis and perspectives. Oxford University Press, Oxford, UK.

Loreau, M., and A. Hector. 2001. Partitioning selection and complementarity in biodiversity experiments. Nature 412:72-76.

Loreau, M., et al. 2001. Biodiversity and ecosystem functioning: current knowledge and future challenges. Science 294:804808.

Mitchell, C. E., D. Tilman, and J. V. Groth. 2002. Effects of grassland plant species diversity, abundance, and composition on foliar fungal disease. Ecology 83:1713-1726.

Mittelbach, G. G., C. F. Steiner, S. M. Scheiner, K. L. Gross, H. L. Reynolds, R. B. Waide, M. R. Willig, S. I. Dodson, and L. Gough. 2001. What is the observed relationship between species richness and productivity. Ecology 82:2381-2396.

Morzaria-Luna, H. N. 2004. Determinants of plant species assemblages in the California marsh plain: implications for 
restoration of ecosystem function. Dissertation. University of Wisconsin, Madison, Wisconsin, USA.

Morzaria-Luna, H., J. C. Callaway, G. Sullivan, and J. B. Zedler. 2004. Relationship between topographic heterogeneity and vegetation patterns in a Californian salt-marsh. Journal of Vegetation Science 15:523-530.

Morzaria-Luna, H. N., and J. B. Zedler. 2007. Does seed availability limit plant establishment during salt marsh restoration? Estuaries and Coasts 30:12-25.

Mulder, C. P. H., D. D. Uliassi, and D. F. Doak. 2001. Physical stress and diversity-productivity relationships: the role of positive interactions. Proceedings of the National Academy of Science 98:6704-6708.

Naeem, S. 2002a. Biodiversity equals instability? Nature 416: 23-24.

Naeem, S. 2002b. Ecosystem consequences of biodiversity loss: the evolution of a paradigm. Ecology 83:1537-1552.

Naeem, S. 2006. Biodiversity and ecosystem functioning in restored ecosystems: extracting principles for a synthetic perspective. Pages 210-237 in D. Falk, M. Palmer, and J. Zedler, editors. Foundations of restoration ecology. Island Press, Washington, D.C., USA.

Naeem, S., K. Hakansson, J. H. Lawton, J. H. Crawley, and L. J. Thompson. 1995. Empirical evidence that declining species diversity may alter the performance of terrestrial ecosystems. Philosophical Transactions of the Royal Society B: Biological Sciences 347:249-262.

Naeem, S., J. M. H. Knops, D. Tilman, K. M. Howe, T. Kennedy, and S. Gale. 2000. Plant diversity increases resistance to invasion in the absence of covarying extrinsic factors. Oikos 91:97-108.

Naeem, S., and S. Li. 1997. Biodiversity enhances ecosystem reliability. Nature 390:507-509.

Naeem, S., L. J. Thompson, S. P. Lawler, J. H. Lawton, and R. M. Woodfin. 1994. Declining biodiversity can alter the performance of ecosystems. Nature 368:734-737.

Naeem, S., L. J. Thompson, S. P. Lawler, J. H. Lawton, and R. M. Woodfin. 1996. Biodiversity and plant productivity in model assemblage of plant species. Oikos 76:259-264.

O'Connor, N. E., and T. P. Crowe. 2005. Biodiversity loss and ecosystem functioning: distinguishing between number and identity of species. Ecology 86:1783-1796.

Petchey, O. L. 2003. Integrating methods that investigate how complementarity influences ecosystem functioning. Oikos 101:323-330.

Petchey, O. L., and K. J. Gaston. 2006. Functional diversity: back to basics and looking forward. Ecology Letters 9:741-758.

Pfisterer, A. B., and B. Schmid. 2002. Diversity-dependent production can decrease the stability of ecosystem functioning. Nature 416:84-86.

Polley, H. W., B. J. Wilsey, and J. D. Derner. 2003. Do species evenness and plant density influence the magnitude of selection and complementarity effects in annual plant species mixtures? Ecology Letters 6:248-256.

Reich, P. B., et al. 2001. Plant diversity enhances ecosystem responses to elevated $\mathrm{CO}_{2}$ and nitrogen deposition. Nature 410:809-812.

Roscher, C., V. M. Temperton, M. Scherer-Lorenzen, M. Schmitz, J. Schumacher, B. Schmid, N. Buchmann, W. W. Weisser, and E.-D. Schulze. 2005. Overyielding in experimental grassland communities - irrespective of species pool or spatial scale. Ecology Letters 8:419-429.

Schmid, B., and A. Hector. 2004. The value of biodiversity experiments. Basic and Applied Ecology 5:535-542.

Schwartz, M. W., C. A. Brigham, J. D. Hoeksema, K. G. Lyons, M. H. Mills, and P. J. van Mantgem. 2000. Linking biodiversity to ecosystem function: implications for conservation ecology. Oecologia 122:297-305.

Spaekova, I., and J. Leps. 2001. Procedure for separating the selection effect from other effects in diversity-productivity relationship. Ecology Letters 4:585-594.
Spehn, E. M., et al. 2005. Ecosystem effects of biodiversity manipulations in European grasslands. Ecological Monographs 75:37-63.

Srivastava, D. S., and M. Vellend. 2005. Biodiversity-ecosystem function research: Is it relevant to conservation? Annual Review of Ecology, Evolution, and Systematics 36:267-294.

Stevens, M. H. H., and W. P. Carson. 2001. Phenological complementarity, species diversity, and ecosystem function. Oikos 92:291-296.

Sullivan, G., and J. B. Zedler. 1999. Functional redundancy among tidal marsh halophytes: a test. Oikos 84:246-260.

Symstad, A. J. 2000. A test of the effects of functional group richness and composition on grassland invasibility. Ecology 81:99-109.

Tilman, D. 1997. Community invasibility, recruitment limitation, and grassland biodiversity. Ecology 78:81-92.

Tilman, D., and J. A. Downing. 1994. Biodiversity and stability in grasslands. Nature 367:363-365.

Tilman, D., J. Knops, D. Wedin, P. Reich, M. Ritchie, and E. Siemann. 1997. The influence of functional diversity and composition on ecosystem processes. Science 277:1300-1302.

Tilman, D., P. B. Reich, and J. M. H. Knops. 2006. Biodiversity and ecosystem stability in a decade-long grassland experiment. Nature 441:629-632.

Tilman, D., P. B. Reich, J. Knops, D. Wedin, T. Mielke, and C. Lehman. 2001. Diversity and productivity in a long-term grassland experiment. Science 294:843-845.

Underwood, A. J. 1997. Experiments in ecology: their logical design and interpretation using analysis of variance. Cambridge University Press, London, UK.

van Ruijven, J., and F. Berendse. 2003. Positive effects of plant species diversity on productivity in the absence of legumes. Ecology Letters 6:170-175.

Vitousek, P. M., and D. U. Hooper. 1993. Biological diversity and terrestrial ecosystem biogeochemistry. Pages 3-14 in E.-D. Schulze and H. A. Mooney, editors. Biodiversity and ecosystem function. Springer-Verlag, New York, New York, USA.

Walker, B., and J. L. Langridge. 2002. Measuring functional diversity in plant communities with mixed life forms: a problem of hard and soft attributes. Ecosystems 5:529-538.

Wardle, D. A. 2001. No observational evidence for diversity enhancing productivity in Mediterranean shrublands. Oecologia 129:620-621.

Wardle, D. A., K. L. Bonner, and K. S. Nicholson. 1997. Biodiversity and plant litter: experimental evidence which does not support the view that enhanced species richness improves ecosystem function. Oikos 79:247-258.

Winer, B. J. 1971. Statistical concepts in experimental design. McGraw-Hill, New York, New York, USA.

Worm, B., et al. 2006. Impacts of biodiversity loss on ocean ecosystem services. Science 314:787-790.

Yachi, S., and M. Loreau. 1999. Biodiversity and ecosystem productivity in a fluctuating environment. Proceedings of the National Academy of Sciences (USA) 96:1463-1468.

Zedler, J. B. 1977. Salt marsh community structure in the Tijuana Estuary, California. Estuarine and Coastal Marine Science 5:39-53.

Zedler, J. B., J. C. Callaway, J. S. Desmond, G. Vivian-Smith, G. D. Williams, G. Sullivan, A. E. Brewster, and B. K. Bradshaw. 1999. Californian salt marsh vegetation: an improved model of spatial pattern. Ecosystems 2:19-35.

Zedler, J. B., J. C. Callaway, and G. Sullivan. 2001. Declining biodiversity: why species matter and how their functions might be restored in Californian tidal marshes. BioScience 51:1005-1017.

Zedler, J. B., and J. M. West. In press. Declining diversity in natural and restored salt marshes: a 30-year study of Tijuana Estuary. Restoration Ecology. 


\section{APPENDIX A}

Randomized-block ANOVA for the effects of assemblage treatment on function, with a priori contrasts $(\mathrm{df}=1)$ comparing solos with sextets, solos with trios, and trios with sextets (Ecological Archives M077-016-A1).

\section{APPENDIX B}

Randomized-block ANOVA for the effects of assemblage treatment on function among the assemblages where Sv was absent, with a priori contrasts $(\mathrm{df}=1)$ comparing solos with sextets, solos with trios, and trios with sextets (Ecological Archives M077-016A2).

\section{APPENDIX C}

Observed yield in shoot AFDM, the net biodiversity effect, the complementarity effect, and selection effect for each trio and sextet (Ecological Archives M077-016-A3).

\section{APPENDIX D}

Observed yield in shoot $\mathrm{N}$ crop, the net biodiversity effect, the complementarity effect, and selection effect for each trio and sextet (Ecological Archives M077-016-A4).

\section{APPENDIX E}

Observed yield in shoot $\mathrm{N}$ concentration, the net biodiversity effect, the complementarity effect, and selection effect for each trio and sextet (Ecological Archives M077-016-A5).

\section{APPENDIX F}

The deviation of assemblage yield from that expected from the performance of its member species grown in solo (Ecological Archives M077-016-A6).

\section{APPENDIX G}

Non-transgressive overyielding, where $D_{\max }$ is the deviation in assemblage yield from that expected relative to the member species with the best solo yield, and $D_{\text {dom }}$ is the deviation from expected relative to the best performing member species' solo yield (Ecological Archives M077-016-A7).

\section{APPENDIX H}

Comparisons of species' shoot AFDM in trios and sextets (Ecological Archives M077-016-A8).

\section{APPENDIX I}

Comparisons of species' shoot N crop in trios and sextets (Ecological Archives M077-016-A9).

\section{APPENDIX J}

Comparisons of species' shoot N concentration in trios and sextets (Ecological Archives M077-016-A10). 